\title{
Open Sesame: How Transition Fibers and the Transition Zone Control Ciliary Composition
}

\author{
Francesc R. Garcia-Gonzalo ${ }^{1}$ and Jeremy F. Reiter ${ }^{2}$ \\ ${ }^{1}$ Departamento de Bioquímica, Facultad de Medicina, and Instituto de Investigaciones Biomédicas Alberto Sols \\ UAM-CSIC, Universidad Autónoma de Madrid, 28029 Madrid, Spain \\ ${ }^{2}$ Department of Biochemistry and Biophysics, and Cardiovascular Research Institute, University of California, \\ San Francisco, San Francisco, California 94158 \\ Correspondence: francesc.garcia@uam.es; jeremy.reiter@ucsf.edu
}

\begin{abstract}
Cilia are plasma membrane protrusions that act as cellular propellers or antennae. To perform these functions, cilia must maintain a composition distinct from those of the contiguous cytosol and plasma membrane. The specialized composition of the cilium depends on the ciliary gate, the region at the ciliary base separating the cilium from the rest of the cell. The ciliary gate's main structural features are electron dense struts connecting microtubules to the adjacent membrane. These structures include the transition fibers, which connect the distal basal body to the base of the ciliary membrane, and the Y-links, which connect the proximal axoneme and ciliary membrane within the transition zone. Both transition fibers and Y-links form early during ciliogenesis and play key roles in ciliary assembly and trafficking. Accordingly, many human ciliopathies are caused by mutations that perturb ciliary gate function.
\end{abstract}

C lia are born from the docking of a mother centriole to a membrane. The interaction of centriole and membrane depends on the centriolar distal appendages, whose tips anchor to the membrane. In the context of ciliogenesis, these membrane-anchored distal appendages are often referred to as transition fibers (TFs) (Fig. 1). After this early ciliogenic step, the nine concentric microtubule triplets in the centriole, now referred to as the basal body, act as templates onto which the nine axonemal microtubule doublets are constructed. Because axoneme growth and disassembly occur only at its distal tip, the basal-most axoneme is the first to form. This proximal region of the cilium, known as the transition zone (TZ), begins at the distal end of the basal body and is defined by the presence of Y-links, bifid fibers connecting each $\mathrm{TZ}$ microtubule doublet to the adjacent membrane (Fig. 1). Perhaps because of their tethering to microtubules, ciliary gate membranes are particularly resistant to detergent extraction and harbor specialized proteinaceous structures like the ciliary necklace (Fig. 1) (Gilula and Satir 1972; Horst et al. 1987).

The ciliary gate sits at the juncture between the basal body and axoneme, between the plas-

Editors: Wallace Marshall and Renata Basto

Additional Perspectives on Cilia available at www.cshperspectives.org

Copyright (C) 2017 Cold Spring Harbor Laboratory Press; all rights reserved; doi: 10.1101/cshperspect.a028134

Cite this article as Cold Spring Harb Perspect Biol 2017;9:a028134 
F.R. Garcia-Gonzalo and J.F. Reiter

A

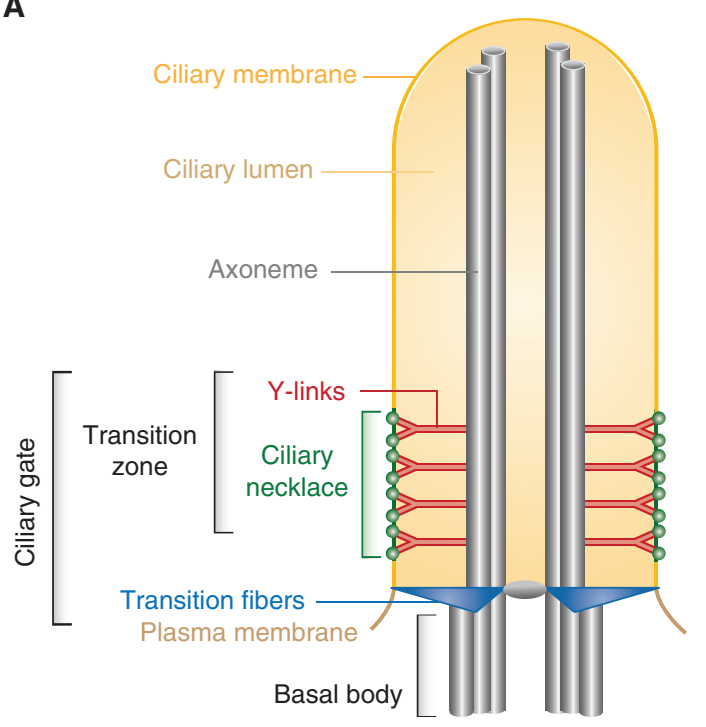

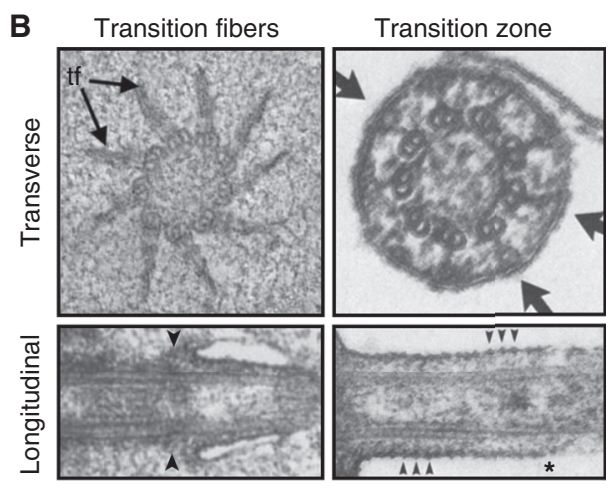

C

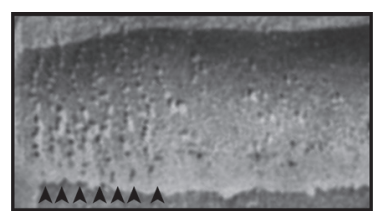

Figure 1. Ultrastructure of the ciliary gate. (A) Schematic showing the different parts of a cilium, with emphasis on the ciliary gate comprised by the transition fibers and the transition zone. (From Reiter et al. 2012; adapted, with permission, from the authors.) (B) Electron microscopic images of the transition fibers and transition zone. Left panels show transition fibers in transverse. (Top, from O'Toole et al. 2003; adapted, with permission, from the American Society for Cell Biology (C) 2003; and longitudinal [bottom] views from Tateishi et al. 2013; reprinted under a Creative Commons License [Attribution-Noncommercial-Share Alike 3.0 Unported license, as described at creativecommons.org/licenses/by-nc-sa/3.0].) Arrows point to transition fibers (tf). Right panels show transverse and longitudinal views of transition zones from rat photoreceptor connecting cilia (From data in Horst et al. 1987; adapted, with permission, from the authors.) Arrows point to Y-links. Asterisk marks the distal end of the transition zone (TZ). (C) Freeze-fracture etching of the ciliary necklace of a rat tracheal cilium. (Image adapted from data in Gilula and Satir 1972.) Arrowheads point to beads in the ciliary necklace.

ma membrane and ciliary membrane, and between the cytosol and ciliary lumen (Fig. 1), and thus is in a position to regulate proteins entering and exiting the cilium. A decade ago, little was known about this region other than its ultrastructure. The last 10 years, however, have changed that: proteomes and interactomes of the ciliary gate and several of its components have been generated, superresolution microscopy has helped localize several gate components, loss of function genetic studies have elucidated functional modules, and many ciliary gate genes have been linked to specific human ciliopathies. We are now at the point where an integrated understanding of how the ciliary gate controls ciliary composition can be anticipated. Below, we review the architecture, composition, function, and disease involvement of each ciliary gate region. We conclude by identifying outstanding questions in the field.

\section{TRANSITION FIBERS}

\section{Transition Fiber Architecture}

Basal bodies start their lives as mother centrioles, distinguished from daughter centrioles by the distal appendages through which they dock to the vesicles that are eventually remodeled into the ciliary membrane (Sorokin 1962; Lu et al. 2015). When associated with the ciliary membrane or its precursors, centriolar distal appendages are referred to as transition fibers (TFs) or alar sheets. Although the former term has gained general acceptance, the latter is evocative of their shape: wing-like trapezoidal sheets 
(Anderson 1972). There are nine TFs, each of which emerges from the distal portion of the Ctubule of the basal body and ends at an electron dense knob at the most proximal ciliary membrane (Fig. 1) (Gibbons and Grimstone 1960; Ringo 1967). Cross sections suggest that there is $\sim 60 \mathrm{~nm}$ between adjacent TFs, enough so that a ribosome, but not a vesicle, might pass between them (Nachury et al. 2010). Because the basal body lumen is obstructed by centrin-2-containing electron dense structures (Fisch and Dupuis-Williams 2011), these spaces between TFs are likely to be the main passageways for macromolecules entering and exiting the cilium.

The TF is comprised of at least five proteins (Graser et al. 2007; Sillibourne et al. 2011; Joo et al. 2013; Tanos et al. 2013). Hierarchical localization analysis shows that Cep83 (also called Ccdc41) is required for the localization of Cep89 (also called Ccdc123 or Cep123) and Sclt1, and the latter is required for localizing Fbf1 and Cep164 (Tanos et al. 2013). Many of these core TF components are required for basal body docking to a membrane and ciliogenesis (Schmidt et al. 2012; Tanos et al. 2013; Joo et al. 2013; Tateishi et al. 2013; Burke et al. 2014; Ye et al. 2014). Another protein, Chibby (Cby1), is recruited to TFs by Cep164 and extends toward the proximal TZ, but is dispensable for at least some forms of ciliogenesis (Voronina et al. 2009; Burke et al. 2014; Lee et al. 2014). In turn, TF localization of all the above proteins requires components of the distal centriole, including Ofd 1 and $\mathrm{C} 2 \mathrm{~cd} 3$, two proteins that, despite their shared role in building the distal appendages, exert opposite effects on centriole length (Singla et al. 2010; Thauvin-Robinet et al. 2014; Ye et al. 2014), and Odf2 (Cenexin), a Cby1 interactor required for the formation of both distal and subdistal centriolar appendages (Ishikawa et al. 2005; Steere et al. 2012; Tateishi et al. 2013). Superresolution microscopy confirms the localization of the above proteins to the TFs, and suggests that Cep89 and Cep164 localize along the length of TFs (Fig. 2A) (Sillibourne et al. 2011; Tanos et al. 2013; Lee et al. 2014; Yang et al. 2015). Despite these advances, how different TF components are spatially ar- ranged to give rise to these structures remains to be determined.

\section{Transition Fiber Functions}

An early step in ciliogenesis is the recruitment of small vesicles to the distal appendages of a mother centriole, the distal appendage vesicles (DAVs). The DAVs fuse to form a larger ciliary vesicle that caps the distal centriole in a process that depends on EHD1 and EHD3 (Lu et al. 2015). Expansion of this ciliary vesicle gives rise to the ciliary membrane, which is assembled in parallel with the axoneme. Axoneme outgrowth is associated with removal from the distal mother centriole of CP110, a protein with both positive and negative roles in early ciliogenesis (Spektor et al. 2007; Tsang et al. 2008; Kobayashi et al. 2011; Yadav et al. 2016). Axoneme formation also involves the construction of the TZ and recruitment of intraflagellar transport (IFT) particles, the microtubule motor-driven complexes that mediate ciliary transport and assembly (Lu et al. 2015).

Disrupting distal appendage formation or function (e.g., interfering with Ofd1, C2cd3, Odf2, Cep164, or Cep83) blocks ciliogenesis and, in all cases where it has been examined, prevents DAV formation (Singla et al. 2010; Schmidt et al. 2012; Joo et al. 2013; Tanos et al. 2013; Tateishi et al. 2013; Burke et al. 2014; Thauvin-Robinet et al. 2014; Ye et al. 2014). Moreover, TFs are essential to remove CP110 from the distal centriole and recruit $\mathrm{TZ}$ and IFT proteins to the ciliary base (Deane et al. 2001; Schmidt et al. 2012; Joo et al. 2013; Tanos et al. 2013; Ćajánek and Nigg 2014; Ye et al. 2014).

Cep164 is a key TF component that promotes ciliogenesis through several mechanisms. First, facilitated by Cby1, Cep164 interacts with Rabin8 to activate Rab8 and promote growth of the ciliary membrane (Knödler et al. 2010; Westlake et al. 2011; Feng et al. 2012; Schmidt et al. 2012; Burke et al. 2014; Lu et al. 2015). Second, Cep164 triggers axoneme extension by recruiting Tau tubulin kinase 2 (Ttbk2) (Goetz et al. 2012; Čajánek and Nigg 2014). For Cep164 to recruit Ttbk2, the phosphoinositide PI(4)P, 
which binds to Cep164 and inhibits its interaction with Ttbk2, must first be depleted near the centriole by the PI(4)P 5-kinase PIPKIy (Xu et al. 2016). Successful Ttbk2 recruitment by Cep164 leads to the removal of CP110 from the distal centriole and the recruitment of IFT components to TFs (Goetz et al. 2012; Čajánek and Nigg 2014). In the absence of Cep164, IFT-B component IFT88 is not recruited to the basal body, preventing ciliogenesis (Schmidt et al. 2012; Cajánek and Nigg 2014). Besides Cep164, other TF proteins also participate in recruiting IFT particles. For example, Fbf1 and Cep83 both bind IFT-B proteins (IFT54 and IFT20, respectively), help recruit them to the TFs, and participate in their crossing into the cilium (Wei et al. 2013; Ye et al. 2014). TF proteins are also needed to recruit TZ proteins to the forming cilium (Schmidt et al. 2012; Tanos et al. 2013; Lu et al. 2015).

Complementing their roles in ciliogenesis, TFs also function in regulating protein trafficking to mature cilia. For example, their role as docking stations for IFT particles en route to cilia holds true both during ciliogenesis and after cilia are constructed (Deane et al. 2001; Wei et al. 2013). Likewise, Inpp5e, a lipid-modified phosphoinositide phosphatase involved in both ciliogenesis and ciliary trafficking, is recruited to the ciliary base by interacting with Cep164 (Humbert et al. 2012; Chávez et al. 2015; Garcia-Gonzalo et al. 2015; Xu et al. 2016).

Thus, TFs recruit a variety of proteins bound for the cilium, but whether TFs actively promote the movement of these proteins through the ciliary gate is unclear. The entry of IFT particles into cilia is not constant: larger amounts of IFT proteins enter the cilium after longer periods of accumulation at the ciliary base, a behavior similar to that of avalanches (Ludington et al. 2013). Whether this avalanche-like behavior depends on accumulation of IFT particles on the TFs remains unclear. TFs (or the spaces between them) might also play a role in the size-dependent entry of soluble proteins into cilia (Kee et al. 2012; Breslow et al. 2013; Lin et al. 2013). The TFs and TZ are good candidates for imparting sieve-like properties to the ciliary gate, but whether either or both do so is unclear. While the trafficking of soluble proteins across the ciliary gate will be described more fully below, TFs affect this process by performing critical roles in both ciliogenesis and protein recruitment to the ciliary base.

\section{TRANSITION ZONE}

\section{Transition Zone Architecture}

Distal to the TFs, the axoneme becomes closely apposed to the ciliary membrane. This apposition is at least partly mediated by Y-links connecting each microtubule doublet of the axoneme to the ciliary membrane (Fig. 1) (Williams et al. 2011; Jensen et al. 2015). In transverse cross sections, Y-links appear as Y-shaped fibers with one end attached to the interface between the $\mathrm{A}$ and $\mathrm{B}$ tubules, and the other two ends docked to the ciliary membrane (Fig. 1). In three dimensions, Y-links were proposed to resemble individual champagne glasses, and more recent electron tomographic reconstructions of Caenorhabditis elegans Ylinks indicate that they form continuous sheets spanning the entire TZ length (Gilula and Satir 1972; Schouteden et al. 2015; Lambacher et al. 2016). Freeze-fracture electron microscopy of the transition zone membrane reveals circumferential bead-like intramembranous particles collectively resembling a necklace (Fig. 1) (Gilula and Satir 1972). In longitudinal sections, the lipid bilayer contacting the Y-links contains similar beads, suggesting that the ciliary necklace is physically associated with the outermost portion of the Y-links (Horst et al. 1987). The necklace need not consist of a single ring of beads: strand number appears to vary with cilia type, ranging from one in some fibroblasts to around 40 in retinal rod cells, whose connecting cilium constitutes an extended TZ (Horst et al. 1987; Fisch and Dupuis-Williams 2011). Necklace strand number correlates with the proximodistal extent of the Y-link region, further suggesting that there is an intimate connection between the two (Fisch and Dupuis-Williams 2011). However, the precise relationship between individual Y-links and necklace beads remains unclear, as is the question of whether necklace strands are separate stacked rings or 
turns of a single spiral spanning the TZ (Reiter et al. 2012; Lambacher et al. 2016).

Many TZ proteins have been identified, most of which have been linked to ciliopathies. Several interactome studies have identified two biochemically distinct TZ protein complexes (Chih et al. 2011; Dowdle et al. 2011; GarciaGonzalo et al. 2011; Sang et al. 2011; Roberson et al. 2015). One of these, the NPHP complex, is mostly involved in the ciliopathy nephronophthisis (NPHP) and includes Nphp1, Nphp4, and Rpgrip1l (Mollet et al. 2005; Arts et al. 2007; Sang et al. 2011). A second complex, involved mostly in Meckel (MKS) and Joubert (JBTS) syndromes and referred to as the MKS complex, includes the three Tectonic proteins (Tctn1, 2, 3), the three B9 domain proteins (Mks1, B9d1, B9d2), the coiled-coil proteins Cc2d2a and Cep290, Ahil and the transmembrane proteins Tmem67, Tmem216, Tmem17, Tmem231, Tmem107, and possibly others such as Tmem237 and Tmem218 (Chih et al. 2011; Garcia-Gonzalo et al. 2011; Huang et al. 2011; Sang et al. 2011; Christopher et al. 2012; Barker et al. 2014; Roberson et al. 2015; Lambacher et al. 2016; Li et al. 2016; Shylo et al. 2016).

The MKS and NPHP complexes interact with each other through a network of looser connections (Fig. 3). An important hub in this network is Cep290, which is part of the MKS complex but also binds Nphp5, a basal body and $\mathrm{TZ}$ protein that associates with two NPHP complex components (Schäfer et al. 2008; Sang et al. 2011; Barbelanne et al. 2013; Barbelanne et al. 2015; Gupta et al. 2015). Inversin is another such hub, linking the MKS and NPHP complexes to the inversin/Nphp3/ Nek8/Anks6/Anks3 complex (Sang et al. 2011; Hoff et al. 2013; Leettola et al. 2014; Czarnecki et al. 2015; Yakulov et al. 2015). Nevertheless, because this latter complex mostly localizes to the inversin compartment, immediately distal from the TZ, it is likely that some of these interactions occur at different times or involve different pools of the same protein (Shiba et al. 2009, 2010; Sang et al. 2011; Czarnecki et al. 2015).

Additional candidate TZ components identified in a proteomic analysis of isolated
Chlamydomonas TZs include several endosomal sorting complex required for transport (ESCRT) proteins (Diener et al. 2015). Because ESCRT proteins mediate vesicle budding from the cell surface in other contexts, they may perform a similar role in cilia (Olmos and Carlton 2016). Consistently, cilia shed extracellular vesicles that, at least in Chlamydomonas, play functionally important roles (Hogan et al. 2009; Bakeberg et al. 2011; Wood et al. 2013; Maguire et al. 2015). ESCRT proteins also mediate the shedding of midbodies during cytokinesis, a process that topologically resembles autotomy, the shedding of Chlamydomonas flagella through microtubule severing at the TZ (Quarmby 2004; Olmos and Carlton 2016).

Other proteins and lipids may cooperate with the established TZ complexes. For example, septins 2 and 7, and possibly others, are part of a ring at or near the $\mathrm{TZ}$ that regulates protein access to cilia (Hu et al. 2010; Kim et al. 2010; Fliegauf et al. 2014). In addition to a distinct protein composition, the TZ domain may also have a distinct lipid composition: the phosphoinositide lipid $\mathrm{PI}(4,5) \mathrm{P}_{2}$ is restricted to the proximal ciliary membrane by the ciliary enzyme Inpp5e (Chávez et al. 2015; Garcia-Gonzalo et al. 2015; Jensen et al. 2015).

Biochemical and genetic approaches have been useful for identifying TZ complexes and their functions, and now superresolution microscopy is beginning to elucidate how they are organized to explain how the TZ controls ciliary composition (Fig. 2B-F) ( Lee et al. 2014; Yang et al. 2015; Lambacher et al. 2016). For example, one form of superresolution microscopy, stimulated emission depletion (STED) microscopy, has shown that MKS (Tmem67, Ahil) and NPHP (Rpgrip1l) complex proteins comprise discontinuous rings transverse to the ciliary axis with a pattern and diameter consistent with ciliary necklace localization (Fig. 2C) (Lee et al. 2014; Lambacher et al. 2016). Along the ciliary axis, MKS (Tctn2, Tmem67, Mks1) and NPHP (Rpgrip1l) complex proteins localize at the same level, 100$200 \mathrm{~nm}$ above the basal body in RPE-1 cells, matching the location of Y-links and ciliary necklace defined by electron microscopy (Fig. 
A

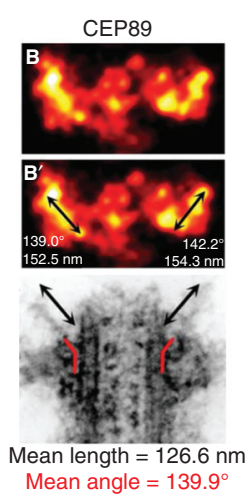

B

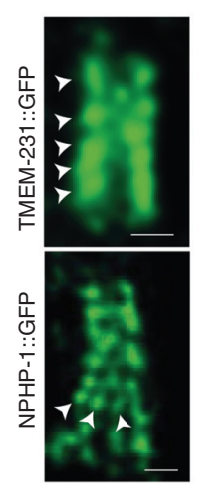

C

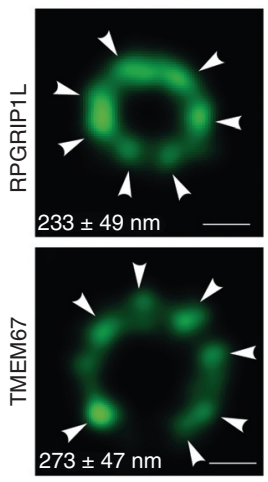

E

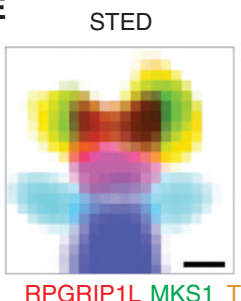

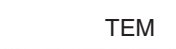

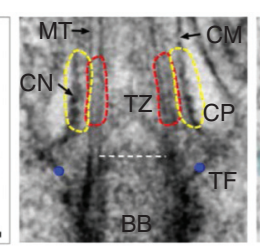

TMEM67 TCTN2 CEP290
Overlay

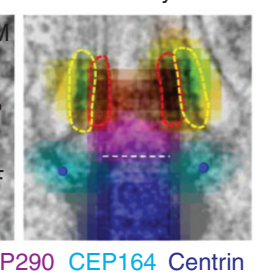

D

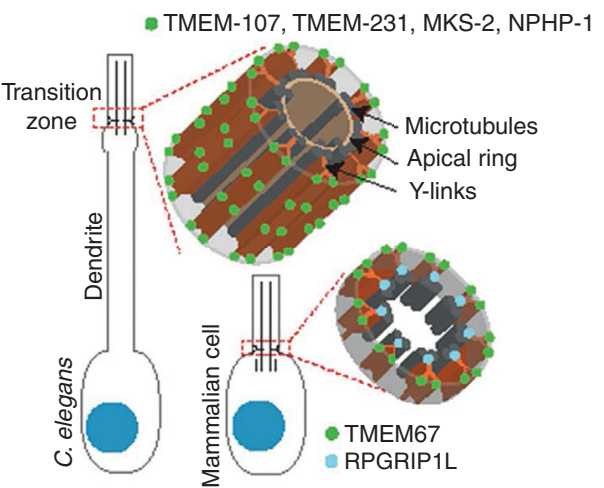

$\mathbf{F}$

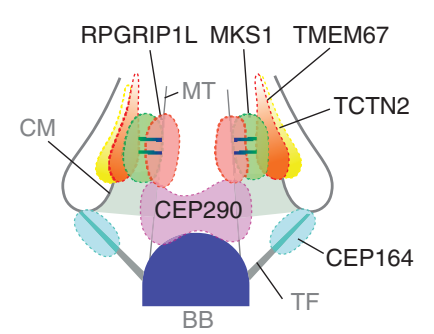

Figure 2. Superresolution microscopy of the ciliary gate. (A) Lateral view of Cep89 localizing to centriolar distal appendages, as observed using photoactivated localization microscopy (PALM). A comparable electron microscopic image is shown at the bottom. Black arrows indicate distal appendages. Red lines indicate the angle at which distal appendages emerge from the centriole. (From Sillibourne et al. 2011; adapted, with permission, from John Wiley and Sons (C) 2011.) (B) Longitudinal views of Caenorhabditis elegans sensory cilia transition zones with the indicated proteins localized using stimulated emission depletion (STED) microscopy. Arrowheads indicate axial and radial periodicity of TMEM-231::GFP and NPHP-1::GFP, respectively. Scale bars, $200 \mathrm{~nm}$. (Panel $B$ is from Lambacher et al. 2016; adapted, with permission, from Nature Publishing Group (C) 2015.) (C) Transverse STED images of cilia from human renal proximal tubule epithelial cells (RPTECs) stained for the indicated proteins. Arrowheads indicate radial periodicity. Ring diameters indicated in each image. Scale bars, $100 \mathrm{~nm}$. (Panel $C$ is from Lambacher et al. 2016; adapted, with permission, from Nature Publishing Group (C) 2015.) (D) Schematic of transition zone (TZ) protein localization in nematode and mammalian cilia. (Panel $D$ is from Lambacher et al. 2016; adapted, with permission, from Nature Publishing Group (C) 2015.) (E) Summary of STED data from human retinal pigment epithelium (RPE) cell cilia. Left panel shows overlayed STED signals, colored as indicated. The center panel shows an electron microscopic image for reference in which ciliary gate structures are indicated. The right panel shows merge. Scale bar, $200 \mathrm{~nm}$. $(F)$ Schematic of the data shown in $E$. (Images $E$ and $F$ are from Yang et al. 2015; reprinted courtesy of Nature Publishing Group under Creative Commons CC-BY Licensing.) MT, Microtubule, CN, ciliary necklace; TF, transition fiber; $\mathrm{CP}$, ciliary pocket; $\mathrm{CM}$, ciliary membrane; $\mathrm{BB}$, basal body.

2E-F) (Yang et al. 2015). As expected, given their transmembrane domains, Tctn2 and Tmem67 rings have the same diameter as that of the ciliary membrane, whereas Mks1, which can bind lipids (our unpublished data), has a slightly smaller diameter. The Rpgrip1l ring has an even smaller diameter, similar to that of the axoneme (Fig. 2C,E) (Yang et al. 2015; Lam- bacher et al. 2016). Thus, these initial observations suggest that the NPHP complex is proximal to the transition zone microtubule sides, consistent with the tubulin-binding ability of both Nphp1 and 4, whereas the MKS complex is mostly associated with the ciliary membrane, as previously predicted from the domain structures of these proteins (Fig. 3) (Otto et al. 2003; 
Mollet et al. 2005; Garcia-Gonzalo and Reiter 2012). Interestingly, whereas Tmem67 and Rpgripll form a single ring in the cilia of a human kidney cell line, longitudinal views of several C. elegans TZ proteins (Tmem107, Tmem231, Tmem216, and Nphp1) display a periodic pattern that is highly reminiscent of ciliary necklace strands or their underlying Y-links (Fig. 2B-D) (Lambacher et al. 2016). Consistent with these proteins being stably anchored to microtubules or other ciliary structures, fluorescence recovery after photobleaching (FRAP) of C. elegans MKS complex proteins (Tmem107, Tmem 216, Cc2d2a) indicates that these proteins do not enter the TZ once it has been assembled (Lambacher et al. 2016).

STED microscopy of mammalian Cep290 positions it more proximally and centrally than Rpgrip1l, suggesting that it may localize to the TZ axoneme (Fig. 2E-F) (Yang et al. 2015). This may also be the case for the C. elegans ortholog of Cep290, which localizes near the TZ axoneme and is required to form the central cylinder, a structure on the lumenal side of the microtubule doublets (Schouteden et al. 2015). In contrast, Chlamydomonas Cep290 localizes to and is involved in the formation of Y-links (Craige et al. 2010). Whether these divergent observations reflect species-specific or cilia-type-specific differences, or whether Cep290, a large protein, can span the TZ axoneme and Y-links, remains to be clarified.

\section{Roles of the Transition Zone in Ciliogenesis}

Loss of function studies of TZ components have revealed two major roles for the TZ: ciliogenesis and the control of ciliary composition. Mouse Nphp1 and Nphp4 mutants, encoding core components of the NPHP complex, show only mild ciliogenic defects affecting two types of highly specialized cilia, photoreceptor cilia and sperm flagella (Jiang et al. 2008, 2009; Won et al. 2011). In contrast, many mutations in genes encoding MKS complex components cause severe ciliogenesis defects in mice, typically leading to embryonic lethality (Weatherbee et al. 2009; Chih et al. 2011; Dowdle et al. 2011; Garcia-Gonzalo et al. 2011; Sang et al. 2011). Despite the severity of the associated embryological defects, many of these MKS mutations do not abrogate ciliogenesis, although this varies by cell type. For instance, Tctn1 mutant embryos lack nodal cilia, have few and dysmorphic neural tube cilia, but display normal rates of ciliogenesis in the limb bud and perineural mesenchyme (Garcia-Gonzalo et al. 2011). In C. elegans, in which only select sensory neurons possess cilia, ciliogenesis is not affected by disruption of either NPHP or $\mathrm{MKS}$ proteins but is strongly perturbed when both an NPHP and an MKS complex component are disrupted (Williams et al. 2008, 2010, 2011; Huang et al. 2011; Jensen et al. 2015; Yee et al. 2015). Electron microscopy in these MKS NPHP double mutants reveals a ciliary gate wherein neither transition fibers nor Y-links are present, leading to membrane detachment from the ciliary axoneme (Huang et al. 2011; Williams et al. 2011; Jensen et al. 2015; Yee et al. 2015). This functional redundancy between the MKS and NPHP complexes is recapitulated in mice, where MKS NPHP doublemutant limbs display more severe disruption of ciliogenesis and patterning defects than those of single MKS mutants (Yee et al. 2015).

Interestingly, the above analysis does not apply to Rpgrip1l, which, despite being part of the biochemical NPHP complex, genetically behaves more like a member of the MKS complex (Sang et al. 2011; Williams et al. 2011). Indeed, Rpgrip1l mouse mutants die embryonically with a phenotype highly reminiscent of those seen for other MKS genes such as Tctn1, Tctn2, B9d1, or $C c 2 d 2 a$, and for double mouse mutants affecting both MKS and NPHP module components (Vierkotten et al. 2007; Dowdle et al. 2011; Garcia-Gonzalo et al. 2011; Sang et al. 2011; Yee et al. 2015). Consistently, human NPHP1 and NPHP4 mutations have only been reported to cause nephronophthisis, whereas RPGRIP1L mutations can also cause more severe ciliopathies such as Meckel and Joubert syndromes (Arts et al. 2007; Delous et al. 2007; Wolf et al. 2007). In C. elegans, Mks-5 is the single ortholog of both RPGRIP1L and RPGRIP1 (an RPGRIP1L paralog, mutations in which cause Leber congenital amaurosis, a severe retinal ciliopathy) (Williams et al. 2011; 
Li 2014; Jensen et al. 2015). Remarkably, although C. elegans Mks-5 mutant TZs completely lack Y-links and fail to localize all known nematode MKS and NPHP module components to the TZ, these mutants still form largely normal ciliary axonemes (Jensen et al. 2015). Ciliary axonemes, however, are disrupted in Mks-5 Nphp-4 double mutants, indicating that MKS- 5 behaves genetically as an MKS module component (Williams et al. 2011). Unlike MKS complex proteins, C. elegans NPHP-1 and NPHP-4 localize not only to TZ but also to TFs, and it may be their function at the TFs that supports ciliogenesis in Mks-5 mutants (Jensen et al. 2015). In single Nphp-4 mutants, which also lack NPHP-1 in their cilia, TFs, Ylinks and ciliary axonemes are present, although both the Y-links and the ciliary axonemes display defects apparent using electron microscopy (Winkelbauer et al. 2005; Jauregui et al. 2008; Jensen et al. 2015; Yee et al. 2015). Together, these data suggest that, in nematodes (but not in many mammalian cell types), ciliogenesis can be supported by TFs alone and that, hence, the TZ functions mainly in the control of cilia composition. How MKS-5/Rpgrip1l affects the MKS complex without being part of it remains unclear. Among the known Rpgrip1l interactors that could mediate effects on the MKS complex are CSPP and Nek4, both of which affect ciliogenesis and localize at or near the TZ (Patzke et al. 2010; Coene et al. 2011).

As mentioned above, vertebrate TZ proteins are required for ciliogenesis in a tissue-specific manner. The TZ forms early in ciliogenesis, soon after membrane docking of the basal body and before axoneme extension (Williams et al. 2011; Lu et al. 2015). Although it is unclear how TZ defects impair subsequent axoneme elongation, one possibility is that a damaged TZ interferes with IFT particle trafficking. Intriguingly, C. elegans Mks-5 mutants display higher IFT speeds than controls in the proximal axoneme but lower speeds in the more distal axoneme, even though overall IFT particle flux remains unaltered (Jensen et al. 2015). The MKS-5-dependent slowing of IFT progress in the proximal axoneme could reflect an interaction between TZ and IFT pro- teins that restrains IFT speed; the TZ-dependent increase in IFT speed in the distal cilium may reflect a TZ-dependent change in the composition or regulation of the IFT particles (Boldt et al. 2011; Zhao and Malicki 2011). Perhaps TZ-dependent regulation of IFT composition or cargo is critical for some forms of ciliogenesis.

Functional ciliogenic interactions have also been found between TZ proteins (of both the MKS and NPHP complexes) and components of the BBSome, an IFT-associated complex (Nachury et al. 2007; Wei et al. 2012; Williams et al. 2014; Yee et al. 2015). For instance, limb bud cells from mice lacking either Tctn1 or Bbs1 are highly ciliated, whereas cells lacking both proteins grow virtually no cilia (Yee et al. 2015). Because the BBSome associates and may travel with IFT particles, one possible explanation for these results is that $\mathrm{TZ}$ proteins and the BBSome have overlapping functions in facilitating IFT-dependent ciliogenesis (Lechtreck et al. 2009; Wei et al. 2012; Williams et al. 2014). For instance, both the TZ and the BBSome could promote loading of ciliogenic cargo, such as tubulins, onto IFT particles (Craft et al. 2015). Alternatively, the BBSome could be required for IFT particles to enter the cilium across a defective TZ region. How ciliary trafficking complexes, such as IFT particles and the BBSome, interact with ciliarygate components, including those of the transition zone, to facilitate ciliogenesis remains to be elucidated.

\section{Roles of the Transition Zone in Soluble Protein} Trafficking

Soluble proteins not associated with the membrane can enter the cilium by diffusion or active transport. Because the ciliary gate behaves as a size-exclusion filter, only small proteins can enter the cilium by diffusion (Kee et al. 2012; Breslow et al. 2013; Lin et al. 2013). Using a chemically inducible diffusion trap at cilia (C-IDTc), proteins with Stokes radii of up to $8 \mathrm{~nm}$ were seen to enter cilia with influx rates decreasing exponentially with increasing Stokes radii (Lin et al. 2013). These data, which were similar in 
both fibroblasts (NIH-3T3) and kidney tubule cells (IMCD3), are consistent with the presence of a molecular sieve spanning $1.4 \mu \mathrm{m}$ along the axis of the ciliary base and with a mean mesh radius of $8 \mathrm{~nm}$ (Lin et al. 2013). Another study using both C-IDTc and in vitro reconstitution of soluble trafficking across the ciliary gate of IMCD3 cells detected no ciliary entry for proteins with Stokes radii above $4.5 \mathrm{~nm}$ (Breslow et al. 2013). However, ciliary entry in this study was monitored for 6-10 min, which, according to the study by Lin et al. (2013), corresponds to the time a 6- to 7-nm protein needs to reach half-maximal accumulation within cilia (Breslow et al. 2013). Hence, the data in these two studies are fairly consistent with one another when time is accounted for. The same can be said of a third study in which $10 \mathrm{kDa}(1.9 \mathrm{~nm})$ but not $40 \mathrm{kDa}(4.8 \mathrm{~nm})$ dextran was found inside cilia $5 \mathrm{~min}$ after microinjection into the cell body of RPE cells (Kee et al. 2012). Last, a fourth study showing that trimeric GFP (Baum et al. 2014) can readily accumulate in the outer segments of transgenic frog photoreceptors can be explained by the fact that trimeric GFP $(5.5 \mathrm{~nm})$, when measured, had been moving across the connecting cilium for a long time (Najafi et al. 2012). Therefore, the ciliary gate appears to behave as a molecular sieve-like barrier, but the exact location and molecular makeup of this barrier are unknown. The data from the Lin et al. (2013) model (1.4- $\mu \mathrm{m}$-long barrier with $8 \mathrm{~nm}$ mean mesh radius) suggests that the entire ciliary gate stretching from the TFs

\section{A}

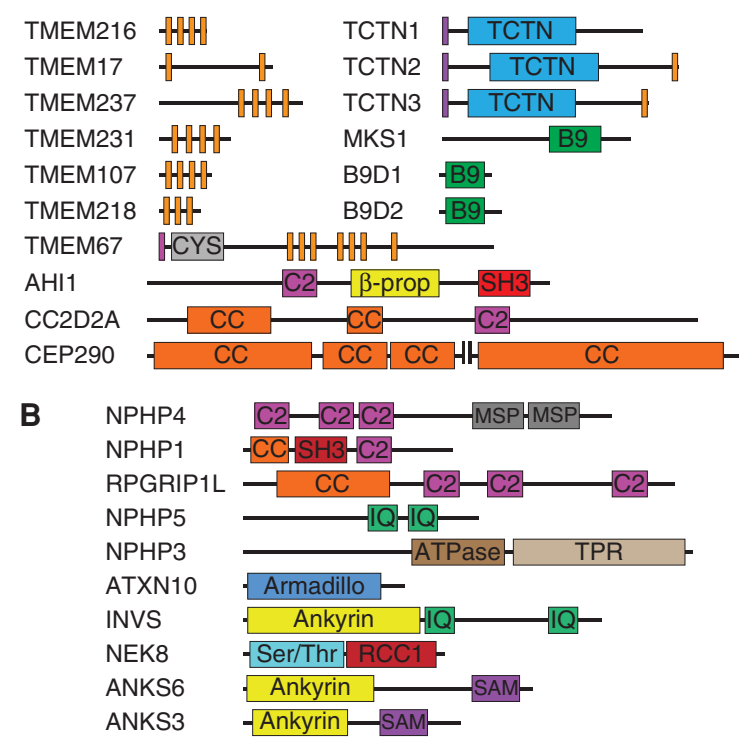

C

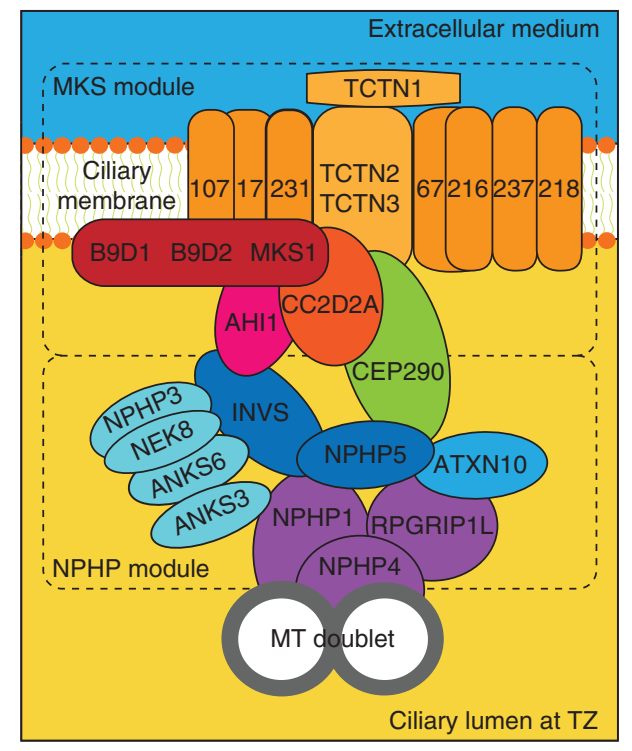

Figure 3. The transition zone interactome. (A) Domain structure of human MKS module proteins. Orange rectangles, transmembrane helices; purple rectangles, signal peptides; TCTN. Tectonic domains (also known as DUF1619); CYS, cysteine-rich domain; CC, coiled-coil; SH3, Src homology- 3 motif; $\beta$-prop, $\beta$-propeller domain. With the exception of CEP290, the schematic lengths scale with amino acid number. (Panel A from Garcia-Gonzalo and Reiter 2012; adapted, with permission, from the authors.) (B) Domain structure of human NPHP module proteins, including those of the inversin subcomplex. MSP, major sperm protein domain; CC, coiled coil; SH3, Src-homology-3 motif; IQ, IQ calmodulin-binding motif; TPR, tetratricopeptide repeats; Armadillo, Armadillo-like domain; Ankyrin, ankyrin repeats; Ser/Thr, serine/threonine kinase domain; RCC1, RCC1-like domain; SAM, sterile $\alpha$ motif. (Panel B from Garcia-Gonzalo and Reiter 2012; adapted, with permission, from the authors.) (C) Model of the MKS and NPHP protein interaction network. TMEM proteins are only indicated by their number. The TCTN and B9 subcomplexes are shown as compact structures with the individual protein names indicated inside. 
through the TZ acts as a sieve, and that the pore size is smaller than the distances between adjacent TFs or Y-links, possibly because of a nonelectron dense meshwork spanning those gaps.

Unlike diffusion, which only small soluble proteins can use to efficiently enter cilia, microtubule motor-dependent transport into and out of cilia is unaffected by cargo size, and depends rather on the ability of the cargo to associate with motor complexes (reviewed in GarciaGonzalo and Reiter 2012). For ciliary entry, ciliary proteins can associate with heterotrimeric kinesin-2 (comprised of Kif3a, Kif3b, and Kap) or with monomeric Kif17, whereas ciliary exit is mediated by cytoplasmic dynein 2 (Verhey et al. 2011). Heterotrimeric kinesin-2, and many of its associated IFT proteins, are required for ciliogenesis, complicating investigation of how these complexes use force and protein-protein interactions to negotiate passage across the TZ. Apart from tubulins, some of the soluble cargos carried by these kinesin-IFT complexes in Chlamydomonas include the outer dynein arms and the partially preassembled radial spoke complexes, two large macromolecular assemblies required for flagellar motility (Qin et al. 2004; Hou et al. 2007; Bhogaraju et al. 2013; Craft et al. 2015). In contrast to trimeric kinesin-2, Kif17 is not required for ciliogenesis and its ciliary entry requires its interactions with both importin- $\beta 2$ and Rab23 (Dishinger et al. 2010; Leaf and Von Zastrow 2015; Lim and Tang 2015). The requirement for importin- $\beta 2$, together with the possible presence of some nucleoporins at the ciliary base and a Ran-GTP gradient across it, has revealed parallels between transport into cilia and transport into nuclei (Dishinger et al. 2010; Kee et al. 2012; Breslow et al. 2013; Takao et al. 2014). The extent of these parallels remains an area of investigation, and has been reviewed elsewhere (Garcia-Gonzalo and Reiter 2012; Reiter et al. 2012).

Roles of the Transition Zone in Membrane Trafficking

Some plasma membrane proteins cannot reach the ciliary base because they are anchored to the cytoskeleton, as is the case of cortical ac- tin-bound podocalyxin (Francis et al. 2011). Many of the plasma membrane proteins that do reach the ciliary base are excluded from the cilium by the TZ, as seen by their presence within cilia only on TZ disruption (Chih et al. 2011; Williams et al. 2011; Jensen et al. 2015; Roberson et al. 2015; Yee et al. 2015). How the TZ membrane prevents the ciliary accumulation of such membrane-associated proteins is unclear but may relate to a low fluidity of the $\mathrm{TZ}$ membrane associated with the abundance of membrane-associated anchors attached to the underlying microtubule cytoskeleton (as reviewed in Nachury et al. 2010). As discussed above, the TZ membrane contains the ciliary necklace, which may contain, among others, the many transmembrane proteins of the MKS complex (e.g., Tmem67, Tmem231, Tmem216, Tmem17, Tmem107, Tctn2, and Tctn3) (Fig. 3). Because septin2 is required for the TZ localization of some of these MKS complex proteins, it is possible that the ciliary septin ring adjoins the ciliary necklace, where it could stabilize MKS complex protein localization (Chih et al. 2011). Consistent with this possibility, both septin2 and B9d1 (an MKS complex protein requiring septin2 for its localization) are required for the ciliary gate to act as a membrane diffusion barrier, slowing down the rate at which transmembrane proteins cross the ciliary gate (Hu et al. 2010; Chih et al. 2011). More extensive reviews on the functions of septins in cilia can be found elsewhere (Hu and Nelson 2011; Garcia-Gonzalo and Reiter 2012; Reiter et al. 2012).

Despite the membrane diffusion barrier at the ciliary gate, many membrane-associated proteins still enter and exit cilia. As with cytosolic proteins, association with trafficking complexes, including microtubule motors and cargo adaptor complexes such as IFT-B, Tulp3IFT-A, and the BBSome, can facilitate the localization of these proteins to the cilium (Nachury et al. 2007; Jin et al. 2010; Mukhopadhyay et al. 2010; Garcia-Gonzalo and Reiter 2012; Mukhopadhyay et al. 2013; Williams et al. 2014). Membrane-associated cargo proteins can interact with these trafficking complexes via ciliary localization sequences (CLSs). For instance, 
multiple ciliary G-protein-coupled receptors (GPCRs) rely on CLSs in their third intracellular loops that directly bind to the BBSome complex, which is itself associated with IFT particles, perhaps explaining why the Tulp3-IFTA complex is also required for the cilia localization of GPCRs (Berbari et al. 2008a,b; Jin et al. 2010; Mukhopadhyay et al. 2010, 2013; Loktev and Jackson 2013; Williams et al. 2014). Ciliary localization of a lipid-anchored ciliary protein, $\mathrm{RP} 2$, requires binding to importin- $\beta 2$, which associates with the Kif17 motor (Dishinger et al. 2010; Hurd et al. 2011). Importin- $\beta 1$ localizes to cilia and interacts with the ciliary form of Crumbs3, Crb3-CLPI, suggesting that it may also work in ciliary targeting (Fan et al. 2007). Kif17 seems to use ankyrin $G$ as an adaptor to mediate the ciliary localization of cyclic nucleotide-gated channels in photoreceptors (Jenkins et al. 2006; Kizhatil et al. 2009).

In addition to using trafficking complexes to enter cilia across the TZ, membrane-associated proteins use trafficking complexes to exit cilia across the TZ. An important example of this involves IFT27, which dissociates from the IFT-B complex inside cilia and acts via Lztfl1 and Arl6 to recruit the BBSome and promote the removal of Hh-mediators Patched 1 and Smoothened (Seo et al. 2011; Eguether et al. 2014; Liew et al. 2014). Another Hh-mediator, Gpr161, accumulates in cilia lacking the BBSome component Bbs1, suggesting that Gpr161 also requires the BBSome to exit cilia (Yee et al. 2015). The BBSome, acting as an IFT cargo, also mediates the ciliary exit of other proteins, such as Chlamydomonas phospholipase $\mathrm{D}$, indicating that the BBSome may have evolutionarily ancient roles in promoting the departure of proteins from cilia (Lechtreck et al. 2009, 2013).

Unlike integral membrane proteins, peripheral membrane proteins can be transiently solubilized by interaction with lipid-binding proteins that themselves cross the ciliary gate, thereby circumventing the $\mathrm{TZ}$ membrane when entering the cilium (Milenkovic et al. 2009). Two such transporter proteins, Unc119b and Pde6d, mediate ciliary targeting of myristoylated and prenylated cargo, respectively (Wright et al. 2011; Humbert et al. 2012; Wätzlich et al. 2013; Thomas et al. 2014; Zhang et al. 2014; Lee and Seo 2015; Zhang et al. 2015). Unc119b recognizes the myristoylated amino-terminal residues of both Nphp3 and Cystin, thereby protecting them from interaction with the lipid bilayer (Wright et al. 2011). Only when bound to cargo can Unc119b enter the cilium across the TZ, where it encounters Arl3, a small GTPbinding protein that binds to and induces the dissociation of the Unc119-cargo complex, thereby allowing the myristoylated cargo to associate with the ciliary membrane (Wright et al. 2011; Zhang et al. 2011; Nakata et al. 2012). In turn, Arl3 activity is regulated by an Arl3-GAP (RP2) and an Arl3-GEF (Arl13b), which regulate its association with GDP or GTP and, therefore, its activity (Wright et al. 2011; Gotthardt et al. 2015). Similarly, Pde6d binds prenylated cargo such as Inpp5e, Grk1, and Pde6, whose intraciliary release depends on RPGR bringing together Arl3.GTP and the loaded cargo receptor (Baehr 2014; Gotthardt et al. 2015; Lee and Seo 2015). Intriguingly, double Unc119 Pde6d mouse knockouts show a partial rescue of the Pde6d mutant phenotype, suggesting that these trafficking systems antagonize each other at some level (Zhang et al. 2014). Despite these fascinating advances, how the lipid-binding proteins Unc119b and Pde6d themselves cross the ciliary gate remains to be elucidated. Other ciliary proteins, such as Arl13b or Calflagin/ FCaBP, require palmitoylation or dual acylation (myristoylation and palmitoylation) of their amino-termini to enter cilia, but how these lipid modifications mediate their ciliary entry is not yet clear (Emmer et al. 2009, 2010; Cevik et al. 2010; Maric et al. 2011).

In summary, much is known about how membrane proteins use their CLSs to associate with specialized ciliary trafficking complexes that cross the ciliary gate, but little is known about how these complexes actually surmount the ciliary necklace, Y-links, septin ring, and other hurdles they may encounter along the way. Besides TZ-negotiating CLSs, ciliary proteins may also contain CLSs that function in the earlier step of bringing them to the ciliary base from other cellular locales. These CLSs have 
been reviewed elsewhere (Garcia-Gonzalo and Reiter 2012). In at least one case, photoreceptor cilia CLSs can even be dispensable, as the connecting cilium is the default destination of Golgi-derived membrane proteins (Baker et al. 2008; Gospe et al. 2010). Whether such bulk transport is a feature of other types of cilia remains to be seen.

\section{Other Roles of the Transition Zone}

Beyond ciliogenesis and trafficking, the TZ may play additional roles in cell morphogenesis and signaling. For example, in C. elegans sensory neurons, $\mathrm{TZ}$ proteins are required for anchoring the $\mathrm{TZ}$ at the tips of dendrites to the extracellular matrix, a process that occurs before axonemes sprout from those TZs (Schouteden et al. 2015). The presence of ESCRT proteins, involved in membrane budding elsewhere in the cell, may reflect a TZ role in ciliary vesicle shedding or in autotomy (ciliary shedding) (Quarmby et al. 2004; Diener et al. 2015). TZ proteins may also be involved in Wnt signaling. Tmem67 and the orphan receptor tyrosine kinase Ror 2 form a TZ complex that binds Wnt5a, a noncanonical Wnt ligand (Abdelhamed et al. 2015). This mechanism may account for the overactivity of canonical Wnt signaling in Tmem67 mutant cells and tissues (Adams et al. 2012; Abdelhamed et al. 2013, 2015; Leightner et al. 2013). Similar effects are observed in the absence of Tmem67-interactor and fellow MKS complex member Tmem216, and in the absence of Tmem237, whose C. elegans ortholog also behaves as a component of the MKS module (Valente et al. 2010; Huang et al. 2011). Forced expression of either Tmem67, Tmem216, or Tmem237 can suppress overactivation of canonical Wnt signaling in Tmem67-null cells, suggesting that these proteins have overlapping functions in restricting Wnt signaling (Huang et al. 2011). Another MKS complex protein, Ahil, binds $\beta$-catenin and helps it translocate into the nucleus, and this activation is impaired by the presence of cilia, which sequester Ahil away from $\beta$-catenin (Lancaster et al. 2009, 2011). Whether Tmem67/216/237 exert their effects through
Ahil, or by affecting the $\beta$-catenin repressor Jade-1 via Nphp4, remains unclear (Borgal et al. 2012). These TZ mechanisms may provide an explanation as to why mutations that block ciliation increase responsiveness to canonical Wnt signals (Gerdes et al. 2007; Corbit et al. 2008).

\section{CILIARY GATE DISEASES}

The genes encoding the components of the ciliary gate are mutated in a diverse range of human ciliopathies (Table 1). Despite having been identified only recently, many TF and distal basal body components are associated with ciliopathies. Mutations in three of these genes (SCLT1, OFD1, and C2CD3) cause orofaciodigital syndrome, characterized by craniofacial dysmorphology and polydactyly (Ferrante et al. 2001, 2006; Adly et al. 2014; Thauvin-Robinet et al. 2014). Ofd 1 and $\mathrm{C} 2 \mathrm{~cd} 3$ interact and colocalize in the distal centriole, where they have antagonistic influences on centriole length and are required for TF formation and ciliogenesis (Singla et al. 2010; Thauvin-Robinet et al. 2014; Ye et al. 2014). Similarly, Sclt1 is a TF protein required for ciliary assembly (Tanos et al. 2013). Mutations in two other TF genes, CEP164 and CEP83, can cause nephronophthisis (NPHP), a cystic kidney disease, sometimes accompanied by other signs such as intellectual disability (Chaki et al. 2012; Failler et al. 2014). Both proteins are required for ciliogenesis and Cep164 can also participate in the DNA damage response, a function it can share with other NPHP proteins (Graser et al. 2007; Chaki et al. 2012; Tanos et al. 2013; Daly et al. 2016). As noted above, C. elegans orthologs of the NPHP proteins Nphp1 and Nphp4 localize in both TFs and TZ (Hildebrandt et al. 1997; Mollet et al. 2002; Otto et al. 2002; Jensen et al. 2015). However, whether the mammalian orthologs are also present or function at TFs is unclear. An individual with a homozygous deletion covering a portion of CEP89 displayed impaired cognitive and neuronal function, but this may be caused by a mitochondrial and not a TF role of Cep89 (van Bon et al. 2013). No 
Table 1. Ciliary-gate diseases

\begin{tabular}{|c|c|c|c|c|c|c|c|c|}
\hline Human gene & Loc & MKS & JBTS & NPHP & SLSN & OFD & BBS & LCA \\
\hline MKS1 & $\mathrm{TZ}$ & MKS1 & - & & & & BBS13 & \\
\hline TMEM216 & $\mathrm{TZ}$ & MKS2 & JBTS2 & & & & & \\
\hline TMEM67 & $\mathrm{TZ}$ & MKS3 & JBTS6 & NPHP11 & & & & \\
\hline CEP290 & $\mathrm{TZ}$ & MKS4 & JBTS5 & NPHP6 & SLSN6 & & BBS14 & LCA10 \\
\hline RPGRIP1L & $\mathrm{TZ}$ & MKS5 & JBTS7 & NPHP8 & & & & \\
\hline$C C 2 D 2 A$ & $\mathrm{TZ}$ & MKS6 & JBTS9 & & & & & \\
\hline NPHP3 & IC & MKS7 & - & NPHP3 & & & & \\
\hline TCTN2 & $\mathrm{TZ}$ & MKS8 & JBTS24 & & & & & \\
\hline B9D1 & $\mathrm{TZ}$ & MKS9 & - & & & & & \\
\hline B9D2 & $\mathrm{TZ}$ & MKS10 & - & & & & & \\
\hline TMEM231 & $\mathrm{TZ}$ & MKS11 & JBTS20 & & & OFD3 & & \\
\hline AHI1 & $\mathrm{TZ}$ & - & JBTS3 & & & & & \\
\hline NPHP1 & $\mathrm{TZ}$ & - & JBTS4 & NPHPI & SLSN1 & & & \\
\hline OFD1 & DC & - & JBTS10 & & & OFD1 & & \\
\hline TCTN1 & $\mathrm{TZ}$ & - & JBTS13 & & & & & \\
\hline TMEM237 & $\mathrm{TZ}$ & - & JBTS14 & & & & & \\
\hline TMEM138 & $\mathrm{TZ}$ & & JBTS16 & & & & & \\
\hline TCTN3 & $\mathrm{TZ}$ & - & JBTS18 & & & OFD4 & & \\
\hline INVS & IC & - & - & NPHP2 & & & & \\
\hline NPHP4 & $\mathrm{TZ}$ & - & & NPHP4 & SLSN4 & & & \\
\hline NPHP5 & $\mathrm{TZ}$ & - & - & NPHP5 & SLSN5 & & & \\
\hline$N E K 8$ & IC & - & - & NPHP9 & & & & \\
\hline CEP164 & $\mathrm{TF}$ & - & - & NPHP15 & & & & \\
\hline ANKS6 & IC & - & - & NPHP16 & & & & \\
\hline СЕР83 & $\mathrm{TF}$ & - & - & NPHP1 8 & & & & \\
\hline$C 2 C D 3$ & DC & - & - & NPHP18 & & OFDM & & \\
\hline
\end{tabular}

Genes in the left column encode proteins mentioned in the text. As shown in the second column, these proteins localize (Loc) to the transition zone (TZ), transition fibers (TF), distal centriole (DC), or inversin compartment (IC). See the text for details and references. Columns three through nine indicate which of the genes cause, when mutated, the following ciliopathies: Meckel-Gruber syndrome (MKS), Joubert syndrome (JBTS), Nephronophthisis (NPHP), Senior-Loken syndrome (SLSN), orofaciodigital syndrome (OFD), Bardet-Biedl syndrome (BBS), and Leber congenital amaurosis (LCA). The numbers correspond to the locus number for each disease. The information in this table was compiled from www.omim.org (last accessed January 30, 2016).

ciliopathic mutations have yet been identified for FBF1, ODF2, and CBY1.

Human pathogenic mutations have been identified for most of the genes encoding TZ proteins. The MKS complex derives its name from Meckel-Gruber syndrome (MKS), an extremely severe ciliopathy, leading to perinatal lethality and characterized by occipital encephalocele, polycystic kidneys, and polydactyly (Hildebrandt et al. 2011). MKS can arise from mutations in MKS1, TMEM216, TMEM67, CEP290, RPGRIP1L, CC2D2A, NPHP3, TCTN2, B9D1, B9D2, TMEM231, KIF14, TCTN3, and TMEM107 (Thomas et al. 2012; Shaheen et al. 2013; Filges et al. 2014; Valente et al. 2014;
Roberson et al. 2015; Shaheen et al. 2015). Of these, all except RPGRIP1L, NPHP3, and KIF14 encode identified components of the MKS complex (Chih et al. 2011; Dowdle et al. 2011; Garcia-Gonzalo et al. 2011; Sang et al. 2011; Roberson et al. 2015; Lambacher et al. 2016). Some of these genes (i.e., TMEM216, TMEM67, CEP290, RPGRIP1L, CC2D2A, TCTN2, TCTN3, and TMEM231) are also mutated in a milder ciliopathy, Joubert syndrome (JBTS), defined by a specific cerebellar malformation, the molar tooth sign, but usually also including polydactyly (Valente et al. 2014; Huppke et al. 2015). The differences in phenotype and severity of these two recessive 
Mendelian syndromes suggest that MKS results from homozygous null mutations in these genes, whereas JBTS results from the involvement of at least one hypomorphic allele (Delous et al. 2007; Mougou-Zerelli et al. 2009; Iannicelli et al. 2010). Hence, MKS may result from more severe dysfunction of the ciliary gate and ciliogenesis than JBTS (Garcia-Gonzalo et al. 2011). Alternatively, coinherited genetic modifiers may account for the phenotypic differences (Roberson et al. 2015). TZ genes are also mutated in NPHP, as is the case for NPHP1, NPHP4, RPGRIP1L, TMEM67, and CEP290 (Hurd and Hildebrandt 2011). Despite the extensive overlap between MKS-, JBTS-, and NPHP-associated genes, the extent to which these syndromes arise from disruption of different functions of the TZ ciliary-gating mechanism is unclear. TZ proteins are mutated in yet other ciliopathies, like OFD, further extending the phenotypic consequences of perturbed ciliary gate function (Thomas et al. 2012; Roberson et al. 2015). As the discrete cellular functions of $\mathrm{TZ}$ proteins become clearer, a better understanding will emerge of how different perturbations of their functions act alone or in combination to give rise to diverse ciliopathies.

\section{CONCLUDING REMARKS}

The last decade has seen great advances in our molecular understanding of the ciliary gate, and the pace of discovery only seems to be increasing. An already visible trend in the field includes the widespread application of superresolution microscopy, structural biology, and reconstitution to obtain high-resolution maps of ciliary gate structures such as TFs, Y-links, and ciliary necklaces (Fig. 2). As this information starts to be integrated, a more detailed picture of ciliary gate dynamics and function will emerge. Another trend is an increasing understanding of how the molecular ciliary composition and structure differs between tissues and species. The lipid composition and function of the transition zone is only starting to be uncovered: recent studies have revealed the presence of a $\mathrm{PI}(4,5) \mathrm{P}_{2}$ gradient at the ciliary base that affects trafficking of ciliary membrane proteins and is dependent on TZ proteins (Chávez et al. 2015; Garcia-Gonzalo et al. 2015; Jensen et al. 2015). The next years should see further developments regarding phosphoinositides and other lipids at the ciliary gate, such as the ones that may bestow it with lipid raft-like properties (Emmer et al. 2010; Follit et al. 2010); and, of course, in this exciting and fast-moving field, one should always expect the unexpected: new ciliary gate functions, new exceptions for previously established rules, and new ways in which the ciliary gate controls the diverse functions of motile and signaling cilia.

\section{REFERENCES}

Abdelhamed ZA, Wheway G, Szymanska K, Natarajan S, Toomes C, Inglehearn C, Johnson CA. 2013. Variable expressivity of ciliopathy neurological phenotypes that encompass Meckel-Gruber syndrome and Joubert syndrome is caused by complex de-regulated ciliogenesis, Shh and Wnt signalling defects. Hum Mol Genet 22: $1358-1372$.

Abdelhamed ZA, Natarajan S, Wheway G, Inglehearn CF, Toomes C, Johnson CA, Jagger DJ. 2015. The MeckelGruber syndrome protein TMEM67 controls basal body positioning and epithelial branching morphogenesis in mice via the non-canonical Wnt pathway. Dis Model Mech 8: 527-541.

Adams M, Simms RJ, Abdelhamed Z, Dawe HR, Szymanska K, Logan CV, Wheway G, Pitt E, Gull K, Knowles MA, et al. 2012. A meckelin-filamin A interaction mediates ciliogenesis. Hum Mol Genet 21: 1272-1286.

Adly N, Alhashem A, Ammari A, Alkuraya FS. 2014. Ciliary genes TBC1D32/C6orf170 and SCLT1 are mutated in patients with OFD type IX. Hum Mutat 35: 36-40.

Anderson RG. 1972. The three-dimensional structure of the basal body from the rhesus monkey oviduct. J Cell Biol 54: 246-265.

Arts HH, Doherty D, van Beersum SE, Parisi MA, Letteboer SJ, Gorden NT, Peters TA, Märker T, Voesenek K, Kartono A, et al. 2007. Mutations in the gene encoding the basal body protein RPGRIP1L, a nephrocystin- 4 interactor, cause Joubert syndrome. Nat Genet 39: 882-888.

Baehr W. 2014. Membrane protein transport in photoreceptors: The function of PDEס: The Proctor lecture. Invest Ophthalmol Vis Sci 55: 8653-8666.

Bakeberg JL, Tammachote R, Woollard JR, Hogan MC, Tuan HF, Li M, van Deursen JM, Wu Y, Huang BQ, Torres VE, et al. 2011. Epitope-tagged Pkhd1 tracks the processing, secretion, and localization of fibrocystin. J Am Soc Nephrol 22: 2266-2277.

Baker SA, Haeri M, Yoo P, Gospe SM III, Skiba NP, Knox BE, Arshavsky VY. 2008. The outer segment serves as a default destination for the trafficking of membrane proteins in photoreceptors. J Cell Biol 183: 485-498.

Barbelanne M, Song J, Ahmadzai M, Tsang WY. 2013. Pathogenic NPHP5 mutations impair protein interaction 
with Cep290, a prerequisite for ciliogenesis. Hum Mol Genet 22: 2482-2494.

Barbelanne M, Hossain D, Chan DP, Peränen J, Tsang WY. 2015. Nephrocystin proteins NPHP5 and Cep290 regulate BBSome integrity, ciliary trafficking and cargo delivery. Hum Mol Genet 24: 2185-2200.

Barker AR, Renzaglia KS, Fry K, Dawe HR. 2014. Bioinformatic analysis of ciliary transition zone proteins reveals insights into the evolution of ciliopathy networks. $B M C$ Genomics 15: 531.

Baum M, Erdel F, Wachsmuth M, Rippe K. 2014. Retrieving the intracellular topology from multi-scale protein mobility mapping in living cells. Nat Commun 5: 4494.

Berbari NF, Lewis JS, Bishop GA, Askwith CC, Mykytyn K. 2008a. Bardet-Biedl syndrome proteins are required for the localization of $\mathrm{G}$ protein-coupled receptors to primary cilia. Proc Natl Acad Sci 105: 4242-4246.

Berbari NF, Johnson AD, Lewis JS, Askwith CC, Mykytyn K. 2008b. Identification of ciliary localization sequences within the third intracellular loop of $\mathrm{G}$ protein-coupled receptors. Mol Biol Cell 19: 1540-1547.

Bhogaraju S, Cajanek L, Fort C, Blisnick T, Weber K, Taschner M, Mizuno N, Lamla S, Bastin P, Nigg EA, et al. 2013. Molecular basis of tubulin transport within the cilium by IFT74 and IFT81. Science 341: 1009-1012.

Boldt K, Mans DA, Won J, van Reeuwijk J, Vogt A, Kinkl N, Letteboer SJ, Hicks WL, Hurd RE, Naggert JK, et al. 2011. Disruption of intraflagellar protein transport in photoreceptor cilia causes Leber congenital amaurosis in humans and mice. J Clin Invest 121: 2169-2180.

Borgal L, Habbig S, Hatzold J, Liebau MC, Dafinger C, Sacarea I, Hammerschmidt M, Benzing T, Schermer B. 2012. The ciliary protein nephrocystin- 4 translocates the canonical Wnt regulator Jade- 1 to the nucleus to negatively regulate $\beta$-catenin signaling. J Biol Chem 287: 25370-25380.

Breslow DK, Koslover EF, Seydel F, Spakowitz AJ, Nachury MV. 2013. An in vitro assay for entry into cilia reveals unique properties of the soluble diffusion barrier. J Cell Biol 203: 129-147.

Burke MC, Li FQ, Cyge B, Arashiro T, Brechbuhl HM, Chen X, Siller SS, Weiss MA, O'Connell CB, Love D, et al. 2014. Chibby promotes ciliary vesicle formation and basal body docking during airway cell differentiation. J Cell Biol 207: 123-137.

Čajánek L, Nigg EA. 2014. Cep164 triggers ciliogenesis by recruiting Tau tubulin kinase 2 to the mother centriole. Proc Natl Acad Sci 111: E2841-E2850.

Cevik S, Hori Y, Kaplan OI, Kida K, Toivenon T, Foley-Fisher C, Cottell D, Katada T, Kontani K, Blacque OE. 2010. Joubert syndrome Arl13b functions at ciliary membranes and stabilizes protein transport in Caenorhabditis elegans. J Cell Biol 188: 953-969.

Chaki M, Airik R, Ghosh AK, Giles RH, Chen R, Slaats GG, Wang H, Hurd TW, Zhou W, Cluckey A, et al. 2012. Exome capture reveals ZNF423 and CEP164 mutations, linking renal ciliopathies to DNA damage response signaling. Cell 150: 533-548.

Chávez M, Ena S, Van Sande J, de Kerchove d'Exaerde A, Schurmans S, Schiffmann SN. 2015. Modulation of ciliary phosphoinositide content regulates trafficking and sonic Hedgehog signaling output. Dev Cell 34: 338-350.
Chih B, Liu P, Chinn Y, Chalouni C, Komuves LG, Hass PE, Sandoval W, Peterson AS. 2011. A ciliopathy complex at the transition zone protects the cilia as a privileged membrane domain. Nat Cell Biol 14: 61-72.

Christopher KJ, Wang B, Kong Y, Weatherbee SD. 2012. Forward genetics uncovers Transmembrane protein 107 as a novel factor required for ciliogenesis and Sonic hedgehog signaling. Dev Biol 368: 382-392.

Coene KL, Mans DA, Boldt K, Gloeckner CJ, van Reeuwijk J, Bolat E, Roosing S, Letteboer SJ, Peters TA, Cremers FP, et al. 2011. The ciliopathy-associated protein homologs RPGRIP1 and RPGRIP1L are linked to cilium integrity through interaction with Nek4 serine/threonine kinase. Hum Mol Genet 20: 3592-3605.

Corbit KC, Shyer AE, Dowdle WE, Gaulden J, Singla V, Chen MH, Chuang PT, Reiter JF. 2008. Kif3a constrains $\beta$-catenin-dependent Wnt signalling through dual ciliary and non-ciliary mechanisms. Nat Cell Biol 10: 70-76.

Craft JM, Harris JA, Hyman S, Kner P, Lechtreck KF. 2015. Tubulin transport by IFT is upregulated during ciliary growth by a cilium-autonomous mechanism. J Cell Biol 208: $223-237$.

Craige B, Tsao CC, Diener DR, Hou Y, Lechtreck KF, Rosenbaum JL, Witman GB. 2010. CEP290 tethers flagellar transition zone microtubules to the membrane and regulates flagellar protein content. J Cell Biol 190: 927-940.

Czarnecki PG, Gabriel GC, Manning DK, Sergeev M, Lemke K, Klena NT, Liu X, Chen Y, Li Y, San Agustin JT, et al. 2015. ANKS6 is the critical activator of NEK8 kinase in embryonic situs determination and organ patterning. Nat Commun 6: 6023.

Daly OM, Gaboriau D, Karakaya K, King S, Dantas TJ, Lalor P, Dockery P, Krämer A, Morrison CG. 2016. Gene-targeted CEP164-deficient cells show a ciliation defect with intact DNA repair capacity. J Cell Sci doi: 10.1242/ jcs. 186221.

Deane JA, Cole DG, Seeley ES, Diener DR, Rosenbaum JL. 2001. Localization of intraflagellar transport protein IFT52 identifies basal body transitional fibers as the docking site for IFT particles. Curr Biol 11: 1586-1590.

Delous M, Baala L, Salomon R, Laclef C, Vierkotten J, Tory K, Golzio C, Lacoste T, Besse L, Ozilou C, et al. 2007. The ciliary gene RPGRIP1L is mutated in cerebello-oculorenal syndrome (Joubert syndrome type B) and Meckel syndrome. Nat Genet 39: 875-881.

Diener DR, Lupetti P, Rosenbaum JL. 2015. Proteomic analysis of isolated ciliary transition zones reveals the presence of ESCRT proteins. Curr Biol 25: 379-384.

Dishinger JF, Kee HL, Jenkins PM, Fan S, Hurd TW, Hammond JW, Truong YN, Margolis B, Martens JR, Verhey KJ. 2010. Ciliary entry of the kinesin-2 motor KIF17 is regulated by importin- $\beta 2$ and RanGTP. Nat Cell Biol 12: 703-710.

Dowdle WE, Robinson JF, Kneist A, Sirerol-Piquer MS, Frints SGM, Corbit KC, Zaghloul NA, van Lijnschoten G, Mulders L, Verver DE, et al. 2011. Disruption of a ciliary B9 protein complex causes Meckel syndrome. Am J Hum Genet 89: 94-110.

Eaton S. 2008. Multiple roles for lipids in the Hedgehog signalling pathway. Nat Rev Mol Cell Biol 9: 437-445.

Eguether T, San Agustin JT, Keady BT, Jonassen JA, Liang Y, Francis R, Tobita K, Johnson CA, Abdelhamed ZA, Lo 
F.R. Garcia-Gonzalo and J.F. Reiter

CW, et al. 2014. IFT27 links the BBSome to IFT for maintenance of the ciliary signaling compartment. Dev Cell 31: 279-290.

Emmer BT, Souther C, Toriello KM, Olson CL, Epting CL, Engman DM. 2009. Identification of a palmitoyl acyltransferase required for protein sorting to the flagellar membrane. J Cell Sci 122: 867-874.

Emmer BT, Maric D, Engman DM. 2010. Molecular mechanisms of protein and lipid targeting to ciliary membranes. J Cell Sci 123: 529-536.

Failler M, Gee HY, Krug P, Joo K, Halbritter J, Belkacem L, Filhol E, Porath JD, Braun DA, Schueler M, et al. 2014. Mutations of CEP83 cause infantile nephronophthisis and intellectual disability. Am J Hum Genet 94: 905-914.

Fan S, Fogg V, Wang Q, Chen XW, Liu CJ, Margolis B. 2007. A novel Crumbs 3 isoform regulates cell division and ciliogenesis via importin $\beta$ interactions. J Cell Biol 178: 387-398.

Feng S, Knödler A, Ren J, Zhang J, Zhang X, Hong Y, Huang S, Peränen J, Guo W. 2012. A Rab8 guanine nucleotide exchange factor-effector interaction network regulates primary ciliogenesis. J Biol Chem 287: 15602-15609.

Ferrante MI, Giorgio G, Feather SA, Bulfone A, Wright V, Ghiani M, Selicorni A, Gammaro L, Scolari F, Woolf AS, et al. 2001. Identification of the gene for oral-facial-digital type I syndrome. Am J Hum Genet 68: 569-576.

Ferrante MI, Zullo A, Barra A, Bimonte S, Messaddeq N, Studer M, Dollé P, Franco B. 2006. Oral-facial-digital type I protein is required for primary cilia formation and leftright axis specification. Nat Genet 38: 112-117.

Filges I, Nosova E, Bruder E, Tercanli S, Townsend K, Gibson WT, Röthlisberger B, Heinimann K, Hall JG, GregoryEvans CY, et al. 2014. Exome sequencing identifies mutations in KIF14 as a novel cause of an autosomal recessive lethal fetal ciliopathy phenotype. Clin Genet 86: 220-228.

Fisch C, Dupuis-Williams P. 2011. Ultrastructure of cilia and flagella-Back to the future! Biol Cell 103: 249-270.

Fliegauf M, Horvath J, von Schnakenburg C, Olbrich H, Müller D, Thumfart J, Schermer B, Pazour GJ, Neumann HP, Zentgraf H, et al. 2006. Nephrocystin specifically localizes to the transition zone of renal and respiratory cilia and photoreceptor connecting cilia. J Am Soc Nephrol 17: 2424-2433.

Fliegauf M, Kahle A, Häffner K, Zieger B. 2014. Distinct localization of septin proteins to ciliary sub-compartments in airway epithelial cells. Biol Chem 395: 151-156.

Follit JA, Li L, Vucica Y, Pazour GJ. 2010. The cytoplasmic tail of fibrocystin contains a ciliary targeting sequence. $J$ Cell Biol 188: 21-28.

Francis SS, Skafianos J, Lo B, Mellman I. 2011. A hierarchy of signals regulates entry of membrane proteins into the ciliary membrane domain in epithelial cells. J Cell Biol 193: $219-233$.

Garcia-Gonzalo FR, Reiter JF. 2012. Scoring a backstage pass: Mechanisms of ciliogenesis and ciliary access. $J$ Cell Biol 197: 697-709.

Garcia-Gonzalo FR, Corbit KC, Sirerol-Piquer MS, Ramaswami G, Otto EA, Seol AD, Bennett CL, Robinson JF, Josifova DJ, Garcia-Verdugo JM, et al. 2011. A transition zone complex regulates mammalian ciliogenesis and ciliary membrane composition. Nat Genet 43: 776-784.

Garcia-Gonzalo FR, Phua SC, Roberson EC, Garcia G III, Abedin M, Schurmans S, Inoue T, Reiter JF. 2015. Phosphoinositides regulate ciliary protein trafficking to modulate Hedgehog signaling. Dev Cell 34: 400-409.

Gerdes JM, Liu Y, Zaghloul NA, Leitch CC, Lawson SS, Kato M, Beachy PA, Beales PL, DeMartino GN, Fisher S, et al. 2007. Disruption of the basal body compromises proteasomal function and perturbs intracellular Wnt response. Nat Genet 39: 1350-1360.

Gibbons IR, Grimstone AV. 1960. On flagellar structure in certain flagellates. J Biophys Biochem Cytol 7: 697-716.

Gilula NB, Satir P. 1972. The ciliary necklace. A ciliary membrane specialization. J Cell Biol 53: 494-509.

Goetz SC, Liem KF Jr, Anderson KV. 2012. The spinocerebellar ataxia-associated gene Tau tubulin kinase 2 controls the initiation of ciliogenesis. Cell 151: 847-858.

Gospe SM III, Baker SA, Arshavsky VY. 2010. Facilitative glucose transporter Glut1 is actively excluded from rod outer segments. J Cell Sci 123: 3639-3644.

Gotthardt K, Lokaj M, Koerner C, Falk N, Giessl A, Wittinghofer A. 2015. A G-protein activation cascade from Arl13B to Arl3 and implications for ciliary targeting of lipidated proteins. eLife 4: e11859.

Graser S, Stierhof YD, Lavoie SB, Gassner OS, Lamla S, Le Clech M, Nigg EA. 2007. Cep164, a novel centriole appendage protein required for primary cilium formation. $J$ Cell Biol 179: 321-330.

Gupta GD, Coyaud É, Gonçalves J, Mojarad BA, Liu Y, Wu Q, Gheiratmand L, Comartin D, Tkach JM, Cheung SW, et al. 2015. A dynamic protein interaction landscape of the human centrosome-cilium interface. Cell 163: 1484-1499.

Hildebrandt F, Otto E, Rensing C, Nothwang HG, Vollmer M, Adolphs J, Hanusch H, Brandis M. 1997. A novel gene encoding an SH3 domain protein is mutated in nephronophthisis type 1. Nat Genet 17: 149-153.

Hildebrandt F, Benzing T, Katsanis N. 2011. Ciliopathies. New Engl J Med 364: 1533-1543.

Hoff S, Halbritter J, Epting D, Frank V, Nguyen TM, van Reeuwijk J, Boehlke C, Schell C, Yasunaga T, Helmstädter M, et al. 2013. ANKS6 is a central component of a nephronophthisis module linking NEK8 to INVS and NPHP3. Nat Genet 45: 951-956.

Hogan MC, Manganelli L, Woollard JR, Masyuk AI, Masyuk TV, Tammachote R, Huang BQ, Leontovich AA, Beito TG, Madden BJ, et al. 2009. Characterization of PKD protein-positive exosome-like vesicles. J Am Soc Nephrol 20: $278-288$.

Horst CJ, Forestner DM, Besharse JC. 1987. Cytoskeletalmembrane interactions: A stable interaction between cell surface glycoconjugates and doublet microtubules of the photoreceptor connecting cilium. J Cell Biol 105: 29732987.

Hou Y, Qin H, Follit JA, Pazour GJ, Rosenbaum JL, Witman GB. 2007. Functional analysis of an individual IFT protein: IFT46 is required for transport of outer dynein arms into flagella. J Cell Biol 176: 653-665. 
Hu Q, Nelson WJ. 2011. Ciliary diffusion barrier: The gatekeeper for the primary cilium compartment. Cytoskeleton (Hoboken) 68: 313-324.

Hu Q, Milenkovic L, Jin H, Scott MP, Nachury MV, Spiliotis ET, Nelson WJ. 2010. A septin diffusion barrier at the base of the primary cilium maintains ciliary membrane protein distribution. Science 329: 436-439.

Huang L, Szymanska K, Jensen VL, Janecke AR, Innes AM, Davis EE, Frosk P, Li C, Willer JR, Chodirker BN, et al. 2011. TMEM237 is mutated in individuals with a Joubert syndrome related disorder and expands the role of the TMEM family at the ciliary transition zone. Am J Hum Genet 89: 713-730.

Humbert MC, Weihbrecht K, Searby CC, Li Y, Pope RM, Sheffield VC, Seo S. 2012. ARL13B, PDE6D, and CEP164 form a functional network for INPP5E ciliary targeting. Proc Natl Acad Sci 109: 19691-19696.

Huppke P, Wegener E, Böhrer-Rabel H, Bolz HJ, Zoll B, Gärtner J, Bergmann C. 2015. Tectonic gene mutations in patients with Joubert syndrome. Eur J Hum Genet 23: 616-620.

Hurd TW, Hildebrandt F. 2011. Mechanisms of nephronophthisis and related ciliopathies. Nephron Exp Nephrol 118: e9-e14.

Hurd TW, Fan S, Margolis BL. 2011. Localization of retinitis pigmentosa 2 to cilia is regulated by Importin $\beta 2 . J$ Cell Sci 124: 718-726.

Iannicelli M, Brancati F, Mougou-Zerelli S, Mazzotta A, Thomas S, Elkhartoufi N, Travaglini L, Gomes C, Ardissino GL, Bertini E, et al. 2010. Novel TMEM67 mutations and genotype-phenotype correlates in meckelin-related ciliopathies. Hum Mutat 31: E1319-E1331.

Ishikawa H, Kubo A, Tsukita S, Tsukita S. 2005. Odf2-deficient mother centrioles lack distal/subdistal appendages and the ability to generate primary cilia. Nat Cell Biol 7: 517-524.

Jauregui AR, Nguyen KC, Hall DH, Barr MM. 2008. The Caenorhabditis elegans nephrocystins act as global modifiers of cilium structure. J Cell Biol 180: 973-988.

Jenkins PM, Hurd TW, Zhang L, McEwen DP, Brown RL, Margolis B, Verhey KJ, Martens JR. 2006. Ciliary targeting of olfactory CNG channels requires the CNGB1b subunit and the kinesin-2 motor protein, KIF17. Curr Biol 16: 1211-1216.

Jensen VL, Li C, Bowie RV, Clarke L, Mohan S, Blacque OE, Leroux MR. 2015. Formation of the transition zone by Mks5/Rpgrip1L establishes a ciliary zone of exclusion (CIZE) that compartmentalises ciliary signalling proteins and controls PIP2 ciliary abundance. EMBO J 34: 2537 2556.

Jiang ST, Chiou YY, Wang E, Lin HK, Lee SP, Lu HY, Wang CK, Tang MJ, Li H. 2008. Targeted disruption of Nphp1 causes male infertility due to defects in the later steps of sperm morphogenesis in mice. Hum Mol Genet 17: 3368-3379.

Jiang ST, Chiou YY, Wang E, Chien YL, Ho HH, Tsai FJ, Lin CY, Tsai SP, Li H. 2009. Essential role of nephrocystin in photoreceptor intraflagellar transport in mouse. Hum Mol Genet 18: 1566-1577.

Jin H, White SR, Shida T, Schulz S, Aguiar M, Gygi SP, Bazan JF, Nachury MV. 2010. The conserved Bardet-Biedl syn- drome proteins assemble a coat that traffics membrane proteins to cilia. Cell 141: 1208-1219.

Joo K, Kim CG, Lee MS, Moon HY, Lee SH, Kim MJ, Kweon HS, Park WY, Kim CH, Gleeson JG, et al. 2013. CCDC41 is required for ciliary vesicle docking to the mother centriole. Proc Natl Acad Sci 110: 5987-5992.

Kee HL, Dishinger JF, Lynne Blasius T, Liu CJ, Margolis B, Verhey KJ. 2012. A size-exclusion permeability barrier and nucleoporins characterize a ciliary pore complex that regulates transport into cilia. Nat Cell Biol 14: 431-437.

Kim SK, Shindo A, Park TJ, Oh EC, Ghosh S, Gray RS, Lewis RA, Johnson CA, Attie-Bittach T, Katsanis N, et al. 2010. Planar cell polarity acts through septins to control collective cell movement and ciliogenesis. Science 329: 13371340.

Kizhatil K, Baker SA, Arshavsky VY, Bennett V. 2009. Ankyrin-G promotes cyclic nucleotide-gated channel transport to rod photoreceptor sensory cilia. Science 323: 1614-1617.

Knödler A, Feng S, Zhang J, Zhang X, Das A, Peränen J, Guo W. 2010. Coordination of Rab8 and Rab11 in primary ciliogenesis. Proc Natl Acad Sci 107: 6346-6351.

Kobayashi T, Tsang WY, Li J, Lane W, Dynlacht BD. 2011. Centriolar kinesin Kif24 interacts with CP110 to remodel microtubules and regulate ciliogenesis. Cell 145: 914925.

Lambacher NJ, Bruel AL, van Dam TJ, Szymanska K, Slaats GG, Kuhns S, McManus GJ, Kennedy JE, Gaff K, Wu KM, et al. 2016. TMEM107 recruits ciliopathy proteins to subdomains of the ciliary transition zone and causes Joubert syndrome. Nat Cell Biol 18: 122-131.

Lancaster MA, Louie CM, Silhavy JL, Sintasath L, Decambre M, Nigam SK, Willert K, Gleeson JG. 2009. Impaired Wnt- $\beta$-catenin signaling disrupts adult renal homeostasis and leads to cystic kidney ciliopathy. Nat Med 15: 1046-1054.

Lancaster MA, Schroth J, Gleeson JG. 2011. Subcellular spatial regulation of canonical Wnt signalling at the primary cilium. Nat Cell Biol 13: 700-707.

Leaf A, Von Zastrow M. 2015. Dopamine receptors reveal an essential role of IFT-B, KIF17, and Rab23 in delivering specific receptors to primary cilia. eLife 4: e06996

Lechtreck KF, Johnson EC, Sakai T, Cochran D, Ballif BA, Rush J, Pazour GJ, Ikebe M, Witman GB. 2009. The Chlamydomonas reinhardtii BBSome is an IFT cargo required for export of specific signaling proteins from flagella. $J$ Cell Biol 187: 1117-1132.

Lechtreck KF, Brown JM, Sampaio JL, Craft JM, Shevchenko A, Evans JE, Witman GB. 2013. Cycling of the signaling protein phospholipase D through cilia requires the BBSome only for the export phase. J Cell Biol 201: 249-261.

Lee JJ, Seo S. 2015. PDE6D binds to the C-terminus of RPGR in a prenylation-dependent manner. EMBO Rep 16: $1581-1582$.

Lee YL, Santé J, Comerci CJ, Cyge B, Menezes LF, Li FQ, Germino GG, Moerner WE, Takemaru K, Stearns T. 2014. Cbyl promotes Ahil recruitment to a ring-shaped domain at the centriole-cilium interface and facilitates proper cilium formation and function. Mol Biol Cell 25: 2919-2933. 
F.R. Garcia-Gonzalo and J.F. Reiter

Leettola CN, Knight MJ, Cascio D, Hoffman S, Bowie JU. 2014. Characterization of the SAM domain of the PKDrelated protein ANKS6 and its interaction with ANKS3. BMC Struct Biol 14: 17.

Leightner AC, Hommerding CJ, Peng Y, Salisbury JL, Gainullin VG, Czarnecki PG, Sussman CR, Harris PC. 2013. The Meckel syndrome protein meckelin (TMEM67) is a key regulator of cilia function but is not required for tissue planar polarity. Hum Mol Genet 22: 2024-2040.

Li T. 2014. Leber congenital amaurosis caused by mutations in RPGRIP1. Cold Spring Harb Perspect Med 5: a017384.

Li C, Jensen VL, Park K, Kennedy J, Garcia-Gonzalo FR, Romani M, De Mori R, Bruel AL, Gaillard D, Doray B, et al. 2016. MKS5 and CEP290 dependent assembly pathway of the ciliary transition zone. PLoS Biol 14: e1002416.

Liew GM, Ye F, Nager AR, Murphy JP, Lee JS, Aguiar M, Breslow DK, Gygi SP, Nachury MV. 2014. The intraflagellar transport protein IFT27 promotes BBSome exit from cilia through the GTPase ARL6/BBS3. Dev Cell 31: 265278.

Lim YS, Tang BL. 2015. A role for Rab23 in the trafficking of Kif17 to the primary cilium. J Cell Sci 128: 2996-3008.

Lin YC, Niewiadomski P, Lin B, Nakamura H, Phua SC, Jiao J, Levchenko A, Inoue T, Rohatgi R, Inoue T. 2013. Chemically-inducible diffusion trap at cilia (C-IDTc) reveals molecular sieve-like barrier. Nat Chem Biol 9: 437-443.

Loktev AV, Jackson PK. 2013. Neuropeptide Y family receptors traffic via the Bardet-Biedl syndrome pathway to signal in neuronal primary cilia. Cell Rep 5: 1316-1329.

Lu Q, Insinna C, Ott C, Stauffer J, Pintado PA, Rahajeng J, Baxa U, Walia V, Cuenca A, Hwang YS, et al. 2015. Early steps in primary cilium assembly require EHD1/EHD3dependent ciliary vesicle formation. Nat Cell Biol 17: 228-240.

Ludington WB, Wemmer KA, Lechtreck KF, Witman GB, Marshall WF. 2013. Avalanche-like behavior in ciliary import. Proc Natl Acad Sci 110: 3925-3930.

Maguire JE, Silva M, Nguyen KC, Hellen E, Kern AD, Hall DH, Barr MM. 2015. Myristoylated CIL-7 regulates ciliary extracellular vesicle biogenesis. Mol Biol Cell 26: 2823-2832.

Maric D, McGwire BS, Buchanan KT, Olson CL, Emmer BT, Epting CL, Engman DM. 2011. Molecular determinants of ciliary membrane localization of Trypanosoma cruzi flagellar calcium-binding protein. I Biol Chem 286: 33109-33117.

Milenkovic L, Scott MP, Rohatgi R. 2009. Lateral transport of Smoothened from the plasma membrane to the membrane of the cilium. J Cell Biol 187: 365-374.

Mollet G, Salomon R, Gribouval O, Silbermann F, Bacq D, Landthaler G, Milford D, Nayir A, Rizzoni G, Antignac C, et al. 2002. The gene mutated in juvenile nephronophthisis type 4 encodes a novel protein that interacts with nephrocystin. Nat Genet 32: 300-305.

Mollet G, Silbermann F, Delous M, Salomon R, Antignac C Saunier S. 2005. Characterization of the nephrocystin/ nephrocystin-4 complex and subcellular localization of nephrocystin- 4 to primary cilia and centrosomes. Hum Mol Genet 14: 645-656.

Mougou-Zerelli S, Thomas S, Szenker E, Audollent S, Elkhartoufi N, Babarit C, Romano S, Salomon R, Amiel
J, Esculpavit C, et al. 2009. CC2D2A mutations in Meckel and Joubert syndromes indicate a genotype-phenotype correlation. Hum Mutat 30: 1574-1582.

Mukhopadhyay S, Wen X, Chih B, Nelson CD, Lane WS, Scales SJ, Jackson PK. 2010. TULP3 bridges the IFT-A complex and membrane phosphoinositides to promote trafficking of $\mathrm{G}$ protein-coupled receptors into primary cilia. Genes Dev 24: 2180-2193.

Mukhopadhyay S, Wen X, Ratti N, Loktev A, Rangell L, Scales SJ, Jackson PK. 2013. The ciliary G-protein-coupled receptor Gpr161 negatively regulates the Sonic hedgehog pathway via cAMP signaling. Cell 152: $210-$ 223.

Myers BR, Sever N, Chong YC, Kim J, Belani JD, Rychnovsky S, Bazan JF, Beachy PA. 2013. Hedgehog pathway modulation by multiple lipid binding sites on the smoothened effector of signal response. Dev Cell 26: 346-357.

Nachury MV, Loktev AV, Zhang Q, Westlake CJ, Peränen J, Merdes A, Slusarski DC, Scheller RH, Bazan JF, Sheffield VC, et al. 2007. A core complex of BBS proteins cooperates with the GTPase Rab8 to promote ciliary membrane biogenesis. Cell 129: 1201-1213.

Nachury MV, Seeley ES, Jin H. 2010. Trafficking to the ciliary membrane: How to get across the periciliary diffusion barrier? Annu Rev Cell Dev Biol 26: 59-87.

Najafi M, Maza NA, Calvert PD. 2012. Steric volume exclusion sets soluble protein concentrations in photoreceptor sensory cilia. Proc Natl Acad Sci 109: 203-208.

Nakata K, Shiba D, Kobayashi D, Yokoyama T. 2012. Targeting of Nphp3 to the primary cilia is controlled by an $\mathrm{N}$-terminal myristoylation site and coiled-coil domains. Cytoskeleton (Hoboken) 69: 221-234.

Olmos Y, Carlton JG. 2016. The ESCRT machinery: New roles at new holes. Curr Opin Cell Biol 38: 1-11.

O’Toole ET, Giddings TH, McIntosh JR, Dutcher SK. 2003. Three-dimensional organization of basal bodies from wild-type and $\delta$-tubulin deletion strains of Chlamydomonas reinhardtii. Mol Biol Cell 14: 2999-3012.

Otto E, Hoefele J, Ruf R, Mueller AM, Hiller KS, Wolf MT, Schuermann MJ, Becker A, Birkenhäger R, Sudbrak R, et al. 2002. A gene mutated in nephronophthisis and retinitis pigmentosa encodes a novel protein, nephroretinin, conserved in evolution. Am J Hum Genet 71: 1161-1167.

Otto EA, Schermer B, Obara T, O’Toole JF, Hiller KS, Mueller AM, Ruf RG, Hoefele J, Beekmann F, Landau $\mathrm{D}$, et al. 2003. Mutations in INVS encoding inversin cause nephronophthisis type 2, linking renal cystic disease to the function of primary cilia and left-right axis determination. Nat Genet 34: 413-420.

Patzke S, Redick S, Warsame A, Murga-Zamalloa CA, Khanna H, Doxsey S, Stokke T. 2010. CSPP is a ciliary protein interacting with Nephrocystin 8 and required for cilia formation. Mol Biol Cell 21: 2555-2567.

Qin H, Diener DR, Geimer S, Cole DG, Rosenbaum JL. 2004. Intraflagellar transport (IFT) cargo: IFT transports flagellar precursors to the tip and turnover products to the cell body. J Cell Biol 164: 255-266.

Quarmby LM. 2004. Cellular deflagellation. Int Rev Cytol 233: 47-91.

Reiter JF, Blacque OE, Leroux MR. 2012. The base of the cilium: Roles for transition fibres and the transition zone 
in ciliary formation, maintenance and compartmentalization. EMBO Rep 13: 608-618.

Ringo DL. 1967. Flagellar motion and fine structure of the flagellar apparatus in Chlamydomonas. J Cell Biol 33: 543-571.

Roberson EC, Dowdle WE, Ozanturk A, Garcia-Gonzalo FR, Li C, Halbritter J, Elkhartoufi N, Porath JD, Cope $\mathrm{H}$, Ashley-Koch A, et al. 2015. TMEM231, mutated in orofaciodigital and Meckel syndromes, organizes the ciliary transition zone. J Cell Biol 209: 129-142.

Rohatgi R, Snell WJ. 2010. The ciliary membrane. Curr Opin Cell Biol 22: 541-546.

Sang L, Miller JJ, Corbit KC, Giles RH, Brauer MJ, Otto EA, Baye LM, Wen X, Scales SJ, Kwong M, et al. 2011. Mapping the NPHP-JBTS-MKS protein network reveals ciliopathy disease genes and pathways. Cell 145: 513-528.

Schäfer T, Pütz M, Lienkamp S, Ganner A, Bergbreiter A, Ramachandran H, Gieloff V, Gerner M, Mattonet C, Czarnecki PG, et al. 2008. Genetic and physical interaction between the NPHP5 and NPHP6 gene products. Hum Mol Genet 17: 3655-3662.

Schmidt KN, Kuhns S, Neuner A, Hub B, Zentgraf H, Pereira G. 2012. Cep164 mediates vesicular docking to the mother centriole during early steps of ciliogenesis. J Cell Biol 199: 1083-1101

Schouteden C, Serwas D, Palfy M, Dammermann A. 2015. The ciliary transition zone functions in cell adhesion but is dispensable for axoneme assembly in C. elegans. J Cell Biol 210: 35-44.

Seo S, Zhang Q, Bugge K, Breslow DK, Searby CC, Nachury MV, Sheffield VC. 2011. A novel protein LZTFL1 regulates ciliary trafficking of the BBSome and Smoothened. PLoS Genet 7: e1002358.

Shaheen R, Ansari S, Mardawi EA, Alshammari MJ, Alkuraya FS. 2013. Mutations in TMEM231 cause MeckelGruber syndrome. J Med Genet 50: 160-162.

Shaheen R, Almoisheer A, Faqeih E, Babay Z, Monies D, Tassan N, Abouelhoda M, Kurdi W, Al Mardawi E, Khali MM, et al. 2015. Identification of a novel MKS locus defined by TMEM107 mutation. Hum Mol Genet 24: 5211-5218.

Shiba D, Yamaoka Y, Hagiwara H, Takamatsu T, Hamada H, Yokoyama T. 2009. Localization of Inv in a distinctive intraciliary compartment requires the C-terminal ninein-homolog-containing region. J Cell Sci 122: 4454.

Shiba D, Manning DK, Koga H, Beier DR, Yokoyama T. 2010. Inv acts as a molecular anchor for Nphp3 and Nek8 in the proximal segment of primary cilia. Cytoskeleton (Hoboken) 67: 112-119.

Shylo NA, Christopher KJ, Iglesias A, Daluiski A, Weatherbee SD. 2016. TMEM107 is a critical regulator of ciliary protein composition and is mutated in orofaciodigital syndrome. Hum Mutat 37: 155-159.

Sillibourne JE, Specht CG, Izeddin I, Hurbain I, Tran P, Triller A, Darzacq X, Dahan M, Bornens M. 2011. Assessing the localization of centrosomal proteins by PALM/ STORM nanoscopy. Cytoskeleton (Hoboken) 68: 619627.
Singla V, Romaguera-Ros M, Garcia-Verdugo JM, Reiter JF 2010. Ofd1, a human disease gene, regulates the length and distal structure of centrioles. Dev Cell 18: 410-424.

Sorokin S. 1962. Centrioles and the formation of rudimentary cilia by fibroblasts and smooth muscle cells. J Cell Biol 15: 363-377.

Spektor A, Tsang WY, Khoo D, Dynlacht BD. 2007. Cep97 and CP110 suppress a cilia assembly program. Cell 130: $678-690$.

Steere N, Chae V, Burke M, Li FQ, Takemaru K, Kuriyama R. 2012. AWnt/ $\beta$-catenin pathway antagonist Chibby binds Cenexin at the distal end of mother centrioles and functions in primary cilia formation. PLoS ONE 7: e41077.

Stinchcombe JC, Randzavola LO, Angus KL, Mantell JM, Verkade P, Griffiths GM. 2015. Mother centriole distal appendages mediate centrosome docking at the immunological synapse and reveal mechanistic parallels with ciliogenesis. Curr Biol 25: 3239-3244.

Takao D, Dishinger JF, Kee HL, Pinskey JM, Allen BL, Verhey KJ. 2014. An assay for clogging the ciliary pore complex distinguishes mechanisms of cytosolic and membrane protein entry. Curr Biol 24: 2288-2294.

Tanos BE, Yang HJ, Soni R, Wang WJ, Macaluso FP, Asara JM, Tsou MF. 2013. Centriole distal appendages promote membrane docking, leading to cilia initiation. Genes Dev 27: 163-168.

Tateishi K, Yamazaki Y, Nishida T, Watanabe S, Kunimoto K, Ishikawa H, Tsukita S. 2013. Two appendages homologous between basal bodies and centrioles are formed using distinct Odf2 domains. J Cell Biol 203: 417-425.

Thauvin-Robinet C, Lee JS, Lopez E, Herranz-Pérez V, Shida T, Franco B, Jego L, Ye F, Pasquier L, Loget P, et al. 2014. The oral-facial-digital syndrome gene $\mathrm{C} 2 \mathrm{CD} 3$ encodes a positive regulator of centriole elongation. Nat Genet 46: 905-911.

Thomas S, Legendre M, Saunier S, Bessières B, Alby C, Bonnière M, Toutain A, Loeuillet L, Szymanska K, Jossic F, et al. 2012. TCTN3 mutations cause Mohr-Majewski syndrome. Am J Hum Genet 91: 372-378.

Thomas S, Wright KJ, Le Corre S, Micalizzi A, Romani M, Abhyankar A, Saada J, Perrault I, Amiel J, Litzler J, et al. 2014. A homozygous PDE6D mutation in Joubert syndrome impairs targeting of farnesylated INPP5E protein to the primary cilium. Hum Mutat 35: 137-146.

Tsang WY, Bossard C, Khanna H, Peränen J, Swaroop A, Malhotra V, Dynlacht BD. 2008. CP110 suppresses primary cilia formation through its interaction with CEP290, a protein deficient in human ciliary disease. Dev Cell 15: 187-197.

Valente EM, Logan CV, Mougou-Zerelli S, Lee JH, Silhavy JL, Brancati F, Iannicelli M, Travaglini L, Romani S, Illi B, et al. 2010. Mutations in TMEM216 perturb ciliogenesis and cause Joubert, Meckel and related syndromes. Nat Genet 42: 619-625.

Valente EM, Rosti RO, Gibbs E, Gleeson JG. 2014. Primary cilia in neurodevelopmental disorders. Nat Rev Neurol 10: $27-36$.

van Bon BW, Oortveld MA, Nijtmans LG, Fenckova M, Nijhof B, Besseling J, Vos M, Kramer JM, de Leeuw N, Castells-Nobau A, et al. 2013. CEP89 is required for mitochondrial metabolism and neuronal function in man and fly. Hum Mol Genet 22: 3138-3151. 
Verhey KJ, Dishinger J, Kee HL. 2011. Kinesin motors and primary cilia. Biochem Soc Trans 39: 1120-1125.

Vierkotten J, Dildrop R, Peters T, Wang B, Rüther U. 2007. Ftm is a novel basal body protein of cilia involved in Shh signalling. Development 134: 2569-2577.

Voronina VA, Takemaru K, Treuting P, Love D, Grubb BR, Hajjar AM, Adams A, Li FQ, Moon RT. 2009. Inactivation of Chibby affects function of motile airway cilia. J Cell Biol 185: 225-233.

Wätzlich D, Vetter I, Gotthardt K, Miertzschke M, Chen YX, Wittinghofer A, Ismail S. 2013. The interplay between RPGR, PDE $\delta$ and Arl2/3 regulate the ciliary targeting of farnesylated cargo. EMBO Rep 14: 465-472.

Weatherbee SD, Niswander LA, Anderson KV. 2009. A mouse model for Meckel syndrome reveals Mks1 is required for ciliogenesis and Hedgehog signaling. Hum Mol Genet 18: 4565-4575.

Wei Q, Zhang Y, Li Y, Zhang Q, Ling K, Hu J. 2012. The BBSome controls IFT assembly and turnaround in cilia. Nat Cell Biol 14: 950-957.

Wei Q, Xu Q, Zhang Y, Li Y, Zhang Q, Hu Z, Harris PC, Torres VE, Ling K, Hu J. 2013. Transition fibre protein FBF1 is required for the ciliary entry of assembled intraflagellar transport complexes. Nat Commun 4: 2750.

Westlake CJ, Baye LM, Nachury MV, Wright KJ, Ervin KE, Phu L, Chalouni C, Beck JS, Kirkpatrick DS, Slusarski DC, et al. 2011. Primary cilia membrane assembly is initiated by Rab11 and transport protein particle II (TRAPPII) complex-dependent trafficking of Rabin8 to the centrosome. Proc Natl Acad Sci 108: 2759-2764.

Williams CL, Winkelbauer ME, Schafer JC, Michaud EJ, Yoder BK. 2008. Functional redundancy of the B9 proteins and nephrocystins in Caenorhabditis elegans ciliogenesis. Mol Biol Cell 19: 2154-2168.

Williams CL, Masyukova SV, Yoder BK. 2010. Normal ciliogenesis requires synergy between the cystic kidney disease genes MKS-3 and NPHP-4. J Am Soc Nephrol 21: 782793.

Williams CL, Li C, Kida K, Inglis PN, Mohan S, Semenec L, Bialas NJ, Stupay RM, Chen N, Blacque OE, et al. 2011. MKS and NPHP modules cooperate to establish basal body/transition zone membrane associations and ciliary gate function during ciliogenesis. J Cell Biol 192: 10231041.

Williams CL, McIntyre JC, Norris SR, Jenkins PM, Zhang L, Pei Q, Verhey K, Martens JR. 2014. Direct evidence for BBSome-associated intraflagellar transport reveals distinct properties of native mammalian cilia. Nat Commun 5: 5813.

Winkelbauer ME, Schafer JC, Haycraft CJ, Swoboda P, Yoder BK. 2005. The C. elegans homologs of nephrocystin- 1 and nephrocystin-4 are cilia transition zone proteins involved in chemosensory perception. J Cell Sci 118: 5575-5587.

Wolf MTF, Saunier S, O’Toole JF, Wanner N, Groshong T, Attanasio M, Salomon R, Stallmach T, Sayer JA, Waldherr $\mathrm{R}$, et al. 2007. Mutational analysis of the RPGRIP1L gene in patients with Joubert syndrome and nephronophthisis. Kidney Int 72: 1520-1526.

Won J, Marín de Evsikova C, Smith RS, Hicks WL, Edwards MM, Longo-Guess C, Li T, Naggert JK, Nishina PM.
2011. NPHP4 is necessary for normal photoreceptor ribbon synapse maintenance and outer segment formation, and for sperm development. Hum Mol Genet 20: 482496.

Wood CR, Huang K, Diener DR, Rosenbaum JL. 2013. The cilium secretes bioactive ectosomes. Curr Biol 23: $906-$ 911.

Wright KJ, Baye LM, Olivier-Mason A, Mukhopadhyay S, Sang L, Kwong M, Wang W, Pretorius PR, Sheffield VC, Sengupta P, et al. 2011. An ARL3-UNC119-RP2 GTPase cycle targets myristoylated NPHP3 to the primary cilium. Genes Dev 25: 2347-2360.

Xu Q, Zhang Y, Wei Q, Huang Y, Hu J, Ling K. 2016. Phosphatidylinositol phosphate kinase PIPKI $\gamma$ and phosphatase INPP5E coordinate initiation of ciliogenesis. Nat Commun 7: 10777.

Yadav SP, Sharma NK, Liu C, Dong L, Li T, Swaroop A. 2016. Centrosomal protein CP110 controls maturation of mother centriole during cilia biogenesis. Development 143: $1491-1501$.

Yakulov TA, Yasunaga T, Ramachandran H, Engel C, Müller B, Hoff S, Dengjel J, Lienkamp SS, Walz G. 2015. Anks3 interacts with nephronophthisis proteins and is required for normal renal development. Kidney Int 87: 11911200.

Yang TT, Su J, Wang WJ, Craige B, Witman GB, Tsou MF, Liao JC. 2015. Superresolution pattern recognition reveals the architectural map of the ciliary transition zone. Sci Rep 5: 14096.

Ye X, Zeng H, Ning G, Reiter JF, Liu A. 2014. C2cd3 is critical for centriolar distal appendage assembly and ciliary vesicle docking in mammals. Proc Natl Acad Sci 111: 2164 2169.

Yee LE, Garcia-Gonzalo FR, Bowie RV, Li C, Kennedy JK, Ashrafi K, Blacque OE, Leroux MR, Reiter JF. 2015. Conserved genetic interactions between ciliopathy complexes cooperatively support ciliogenesis and ciliary signaling. PLoS Genet 11: e1005627.

Zhang H, Liu XH, Zhang K, Chen CK, Frederick JM, Prestwich GD, Baehr W. 2004. Photoreceptor cGMP phospho-

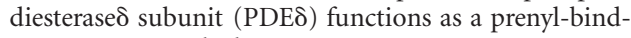
ing protein. J Biol Chem 279: 407-413.

Zhang H, Li S, Doan T, Rieke F, Detwiler PB, Frederick JM, Baehr W. 2007. Deletion of $\operatorname{PrBP} / \delta$ impedes transport of GRK1 and PDE6 catalytic subunits to photoreceptor outer segments. Proc Natl Acad Sci 104: 8857-8862.

Zhang H, Constantine R, Vorobiev S, Chen Y, Seetharaman J, Huang YJ, Xiao R, Montelione GT, Gerstner CD, Davis MW, et al. 2011. UNC119 is required for G protein trafficking in sensory neurons. Nat Neurosci 14: 874-880.

Zhang H, Frederick JM, Baehr W. 2014. Unc119 gene deletion partially rescues the GRK1 transport defect of Pde6d $^{-/-}$cones. Adv Exp Med Bio 801: 487-493.

Zhang H, Hanke-Gogokhia C, Jiang L, Li X, Wang P, Gerstner CD, Frederick JM, Yang Z, Baehr W. 2015. Mistrafficking of prenylated proteins causes retinitis pigmentosa 2. FASEB J 29: $932-942$.

Zhao C, Malicki J. 2011. Nephrocystins and MKS proteins interact with IFT particle and facilitate transport of selected ciliary cargos. EMBO J 30: 2532-2544. 


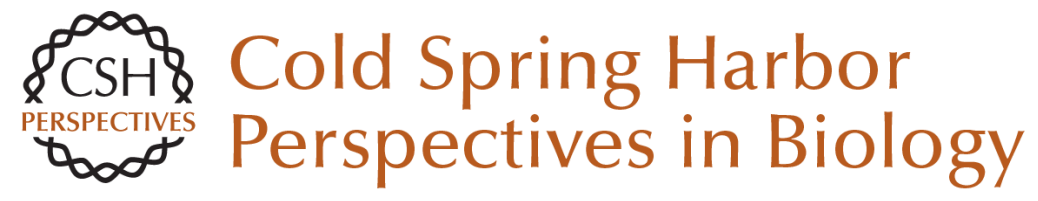

\section{Open Sesame: How Transition Fibers and the Transition Zone Control Ciliary Composition}

Francesc R. Garcia-Gonzalo and Jeremy F. Reiter

Cold Spring Harb Perspect Biol 2017; doi: 10.1101/cshperspect.a028134 originally published online October 21, 2016

\section{Subject Collection Cilia}

Ciliary Mechanisms of Cyst Formation in

Polycystic Kidney Disease Ming Ma, Anna-Rachel Gallagher and Stefan Somlo

Photoreceptor Cilia and Retinal Ciliopathies Kinga M. Bujakowska, Qin Liu and Eric A. Pierce

G-Protein-Coupled Receptor Signaling in Cilia Kirk Mykytyn and Candice Askwith

Evolution of Cilia David R. Mitchell

Transition Zone Migration: A Mechanism for Cytoplasmic Ciliogenesis and Postaxonemal Centriole Elongation

Tomer Avidor-Reiss, Andrew Ha and Marcus L. Basiri

Cilia and Obesity Christian Vaisse, Jeremy F. Reiter and Nicolas F. Berbari

\section{Posttranslational Modifications of Tubulin and} Cilia

Dorota Wloga, Ewa Joachimiak, Panagiota Louka, et al.
Cilia in Left-Right Symmetry Breaking

Kyosuke Shinohara and Hiroshi Hamada

Discovery, Diagnosis, and Etiology of Craniofacial

Ciliopathies

Elizabeth N. Schock and Samantha A. Brugmann

Axoneme Structure from Motile Cilia Takashi Ishikawa

Cilia and Ciliopathies in Congenital Heart Disease Nikolai T. Klena, Brian C. Gibbs and Cecilia W. Lo

Sperm Sensory Signaling Dagmar Wachten, Jan F. Jikeli and U. Benjamin Kaupp

Primary Cilia and Coordination of Receptor Tyrosine Kinase (RTK) and Transforming Growth Factor $\beta$ (TGF- $\beta$ ) Signaling

Soren T. Christensen, Stine K. Morthorst, Johanne $B$. Mogensen, et al.

Primary Cilia and Mammalian Hedgehog Signaling Fiona Bangs and Kathryn V. Anderson

For additional articles in this collection, see http://cshperspectives.cshlp.org/cgi/collection/

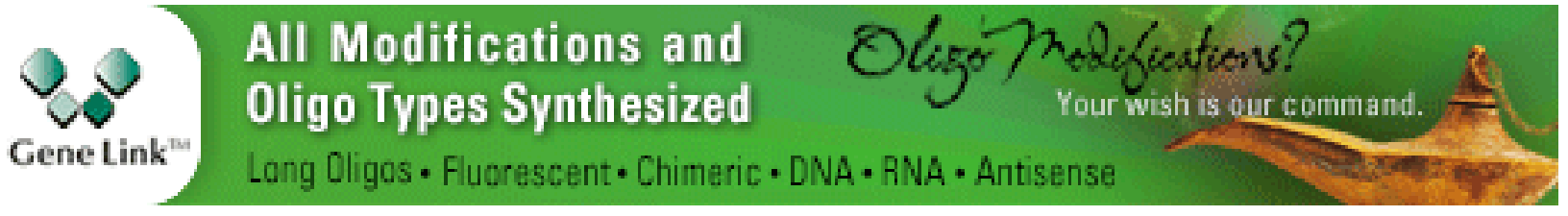


Radial Spokes--A Snapshot of the Motility Regulation, Assembly, and Evolution of Cilia and Flagella

Xiaoyan Zhu, Yi Liu and Pinfen Yang
Cilia and Mucociliary Clearance

Ximena M. Bustamante-Marin and Lawrence E. Ostrowski

For additional articles in this collection, see http://cshperspectives.cshlp.org/cgi/collection/

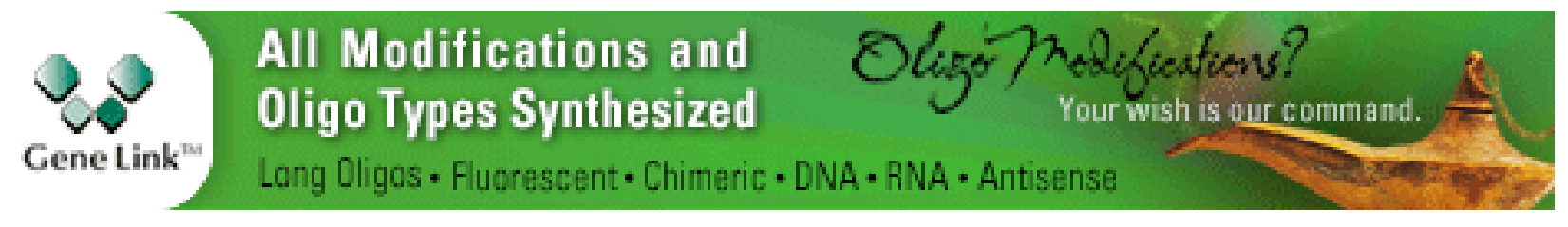

Copyright @ 2017 Cold Spring Harbor Laboratory Press; all rights reserved 